Frey S \& Herbst P (2014) The Influence of Buy-side Analysts on Mutual Fund Trading, Journal of Banking and Finance, 49, pp. 442-458.

This is the peer reviewed version of this article

NOTICE: this is the author's version of a work that was accepted for publication in Journal of Banking and Finance. Changes resulting from the publishing process, such as peer review, editing, corrections, structural formatting, and other quality control mechanisms may not be reflected in this document. Changes may have been made to this work since it was submitted for publication. A definitive version was subsequently published in Journal of Banking and Finance, [VOL 49 (2014)] DOI: http://dx.doi.org/10.1016/j.jbankfin.2014.01.007 


\section{Accepted Manuscript}

The Influence of Buy-side Analysts on Mutual Fund Trading

Stefan Frey, Patrick Herbst

PII:

S0378-4266(14)00021-1

DOI:

http://dx.doi.org/10.1016/j.jbankfin.2014.01.007

Reference:

JBF 4326

To appear in: $\quad$ Journal of Banking \& Finance

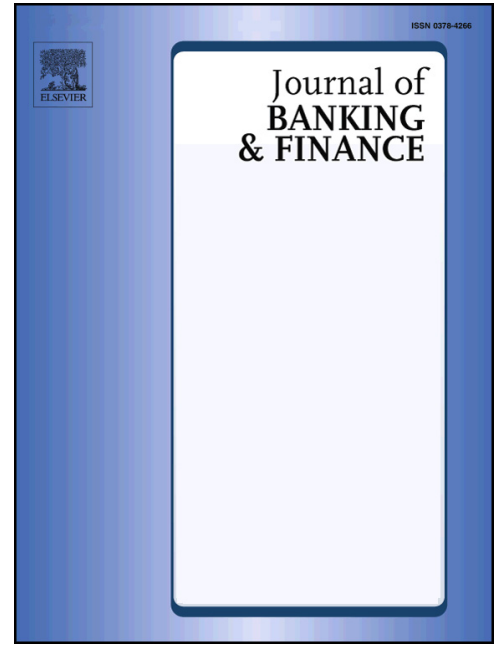

Received Date: $\quad 13$ July 2013

Please cite this article as: Frey, S., Herbst, P., The Influence of Buy-side Analysts on Mutual Fund Trading, Journal of Banking \& Finance (2014), doi: http://dx.doi.org/10.1016/j.jbankfin.2014.01.007

This is a PDF file of an unedited manuscript that has been accepted for publication. As a service to our customers we are providing this early version of the manuscript. The manuscript will undergo copyediting, typesetting, and review of the resulting proof before it is published in its final form. Please note that during the production process errors may be discovered which could affect the content, and all legal disclaimers that apply to the journal pertain. 


\title{
The Influence of Buy-side Analysts on Mutual Fund Trading*
}

\author{
Stefan Frey ${ }^{\dagger}$ \\ Leibniz University Hannover and CFR Cologne
}

\author{
Patrick Herbst ${ }^{\ddagger}$ \\ University of Stirling
}

\begin{abstract}
We present evidence on the trading and performance impact of buy-side analysts. Using data provided by a large global asset manager, we relate buy-side analysts' recommendations to fund transactions on a daily basis. We show that buy-side analysts significantly influence trading decisions: Fund managers strongly follow recent recommendation revisions, even after controlling for other trading determinants. Positive abnormal returns to buy-side analysts' revisions are also reflected in the performance of mutual fund trades: Trades triggered by buy-side recommendations have higher returns than other trades. Overall, the impact of buy-side analysts is more pronounced than that of sell-side analysts.
\end{abstract}

Keywords: Buy-side analysts, analyst recommendations, mutual funds, investment decisions, investment performance

JEL classification: G23, G11, G29, M41

${ }^{*}$ We thank Bruno Biais, Carsten Bienz, Guido Friebel, Joachim Grammig, Harald Hau, Stephan Jank, Alexander Kempf, Terrance Odean, Blake Phillips, Stefan Ruenzi, Noah Stoffman, Monika Trapp, Uwe Walz, Josef Zechner, two anonymous reviewers, as well as seminar and conference participants at NHH Bergen, University of Cologne, University of Frankfurt, the Financial Management Association Annual Meeting in Atlanta, the IFABS Conference in Nottingham, the European Retail Investment Conference in Stuttgart, the French Finance Association meeting in Paris, the German Finance Society meeting in Frankfurt, the INFINITI Conference in Dublin, Multinational Finance Society Annual Meeting in Barcelona, and the ISCTE Business School Finance Conference in Lisbon for helpful comments and suggestions We also gratefully acknowledge the data provision by an asset management firm. The usual disclaimer applies.

†Institute of Money and International Finance, Königsworther Platz 1, 30167 Hannover, Germany. Financial support from the Deutsche Forschungsgemeinschaft (DFG) is gratefully acknowledged.

${ }^{\ddagger}$ Corresponding author; Accounting and Finance Division, Stirling Management School, University of Stirling, Stirling, FK9 4LA, UK; email: patrick.herbst@stir.ac.uk. 


\section{Introduction}

The asset management industry is responsible for a large amount of capital invested on behalf of its clients: Globally, \$53.4 trillion - almost 110\% of world GDP - were under management in 2006, \$24.3 trillion invested in equities alone. ${ }^{1}$ Professional money managers rely on various sources of information in order to guide their investment decisions. In equity markets, sell-side analysts employed by brokerage firms and investment banks as well as analysts employed by independent research providers are a prominent source of information. However, investment management firms also employ their own so-called buyside analysts as an internal source of investment ideas. Although less visible than sell-side analysts, these internal analysts account for a significant share of the overall spending on equity research: According to the advisory firm Tabb Group (2006), US and UK asset managers spent $\$ 7.7$ billion on internal and $\$ 7.1$ billion on external research in 2006 . In the period 2000 to 2002, US equity funds' self-reported weight put on in-house analysts averages $73 \%$ to $75 \%$ (see Cheng, Liu, and Qian, 2006). While sell-side analysts have been analyzed with scrutiny by investors, regulators and academics (see Boni and Womack, 2003), buy-side analysts have received far less attention. Little is known about the impact of these internal analysts relative to external analysts in money managers' investment process so far.

We empirically analyze how the information provided by buy-side analysts affects the investment decisions of professional money managers. Specifically, we approach the following questions: To what degree do managers follow their in-house analysts' recommendations? To what degree do they follow the recommendations issued by sell-side research analysts, which represent public information in the market? What are the performance implications of this behavior? Answers to these questions provide evidence on the value of internal analysts as an important organizational aspect of many asset management firms. To address them, we use a proprietary data set from a large, globally active asset management firm. The data is - to our knowledge - unique in its details. We observe in-house analyst recommendations and changes therein as well as fund positions, transactions and money flows on a daily basis for a set of European equity mutual funds between 2004 and 2007.

Our results show that buy-side analysts (BSAs) have a statistically and economically significant effect on the trading behavior of fund managers. Buy transactions coincide largely with more favorable internal stock recommendations: The direction of trades in a

\footnotetext{
${ }^{1}$ Estimates by the World Bank and the Boston Consulting Group (2007).
} 
stock matches those of a prior recommendation change in almost $90 \%$ of the cases during the week following the new recommendation. Even after controlling for other trading influences (most notably fund flows and sell-side recommendations), we find that, for example, recent recommendation upgrades (downgrades) induce a same-directional increase (decrease) in the probability of a stock purchase of 52 (24) percentage points. This effect is considerably larger than the effect of sell-side analysts (SSAs) on transactions.

The relative impact of BSAs and SSAs is consistent with the two types of analysts providing fund managers with, respectively, private and public investment signals. Investors receiving both types of signals react more strongly to the private signal. ${ }^{2}$ Public signals will be more reflected in stock prices than private ones as a larger set of investors observe and responds to public signals. As the investor's private signal is revealed less in prices, his response to this signal should be stronger (unless its precision is too low). Our findings reflect this differential reaction to public and private signals.

The analysis of returns to recommendation revisions and fund manager transactions suggests that BSAs also positively impact trading performance for our sample funds. Recommendation upgrades by BSAs yield positive abnormal returns while downgrades show negative abnormal returns. The difference in returns is about 2.0 percentage points over a one month horizon. Similarly, fund transactions around recommendation revisions yield positive abnormal return differences of 1.8 to 2.0 percentage points for holding periods of one to two months. More importantly, these transactions yield higher return differences than transactions that either occur around SSA revisions or that cannot be attributed to analyst revisions. The transaction impact of BSAs thus also leads to a positive performance impact for our sample funds.

There exists a significant strand of the literature analyzing research analysts and their value for investments. Most of the empirical contributions here focus on the ability, behavior and incentives of SSAs (see e.g. Womack, 1996; Barber, Lehavy, McNichols, and Trueman, 2001; Irvine, 2004; Ivkovic and Jegadeesh, 2004; Jegadeesh, Kim, Krische, and Lee, 2004; Barber, Lehavy, and Trueman, 2007; Mokoaleli-Mokoteli, Taffler, and Agarwal, 2009; Fang and Yasuda, 2013). Given the private nature of the data, there is hardly any empirical work on BSAs. The papers by Groysberg, Healy, and Chapman (2008), Groysberg, Healy, Serafeim, and Shanthikumar (2013), and Gray, Crawford, Price, and Johnson

\footnotetext{
${ }^{2}$ To have some investment value, the "public" signal needs to be imperfectly observable, e.g. due to liquidity trades (see e.g. Grossman and Stiglitz, 1980; Kyle, 1985). Kacperczyk and Seru (2007) and Chen and Wilhelm (2012) provide models incorporating private and public signals.
} 
(2012) are notable exceptions. Groysberg et al. (2008, 2013) use proprietary data from a US asset management firm in order to compare recommendations and earnings estimates by BSAs and SSAs. They show that earnings estimates by BSAs are less precise than those by SSAs (Groysberg et al., 2008). Similarly, the investment value of BSA recommendations seems lower than the value of the sell-side recommendations (Groysberg et al., 2013). However, Groysberg et al. (2013) show that the latter difference is attributable to differences in buy-side and sell-side coverage. Once this difference is taken into account, their results suggest no performance difference between the two analyst groups.

Our results on analyst recommendation performance are quite similar to those of Groysberg et al. (2013), with BSA recommendations performing even slightly better than SSAs based on a sample of stocks covered by both groups. However, rather than comparing the analyst groups, our contribution is in identifying the performance effect of analyst recommendations as reflected in mutual fund trades. As BSA recommendations are private information, it is only through these trades that their value is realized.

Gray et al. (2012) analyze the value of recommendations by BSAs from a large set of (hedge) funds, issued on a social network targeted to investment professionals. They find that recommendations publicized have investment value, but that fund managers front-run these recommendations. As we are able to relate recommendations and trades on a daily, and thus more timely basis, our paper specifically shows how closely BSA recommendations are followed by fund managers and how this creates value in fund portfolios.

Another strand of related literature analyzes the investment behavior of money managers, specifically the role of public and private information for fund managers. Contributions in this strand are either theoretical (see e.g. Kyle, 1989; Chen and Wilhelm, 2012), focus on public information (e.g. Busse, Green, and Jegadeesh, 2012; Franck and Kerl, 2013), or try to infer the use of private information indirectly (see e.g. Cheng et al., 2006; Kacperczyk and Seru, 2007; Pomorski, 2008). Both Busse et al. (2012) (for the US) and Franck and Kerl (2013) (for Europe) show that fund managers' trades are affected by revisions in SSA recommendations. In addition, the results by Franck and Kerl (2013) suggest that by following these revisions, fund managers realize positive returns.

Kacperczyk and Seru (2007) find that US fund managers follow the sell- side to different degrees. However, their results show that fund managers whose portfolio changes are less correlated with SSA recommendations have better fund performance. The authors attribute this to higher manager skills which yield better private information (or private interpretation of public signals). Typically, BSAs are an important source of such informa- 
tion. Cheng et al. (2006) analyze the role of BSAs by using funds' self-reported weight put on internal research. Analyzing fund performance, they find some evidence that higher use of BSAs yields higher fund performance. Being able to directly link BSA revisions and fund manager transactions for the first time, we show that BSAs do indeed provide important and valuable information to fund managers. And although specific sets of relevant SSAs also have positive trading and performance impact, BSAs can be shown to have a larger impact.

Overall, our paper adds to the existing literature by bridging the above strands of the literature. We provide further evidence on the value of BSA versus SSA revisions, and, more importantly, how this value is reflected in fund manager behavior and trading performance. Our analysis thus represents a first step in quantifying the role of buy-side analysts in the return generating process. The value of relying on internal analyst teams is an important determinant for the organization of asset management activities. Similarly, our paper is also relevant for fund investors gauging the benefits of choosing asset managers with internal research capabilities (at potentially higher management cost).

The paper is structured as follows. Section 2 describes our data set. In section 3 , we analyze the impact of BSAs and SSAs on the trading behavior of fund managers. Section 4 then considers analysts' performance impact. Section 5 estimates the value generated by BSAs for the asset management firm. Section 6 concludes.

\section{Data and sample}

\subsection{Data}

The analysis combines data from both public and private sources. A global asset management firm which belongs to the top ten global asset managers in terms of assets under management is the main data provider. From one of their European offices, we obtained a rich set of information on their mutual funds and buy-side analysts. This data is augmented by stock and sell-side analyst information from Thomson Reuters.

Sample funds: We use a sample of 14 equity funds investing in European equities between June 2004 and December 2007. All these funds are managed by individual fund managers who belong to the firm's European equities team. Managers of a fund can change over time. Most fund managers also manage institutional equity portfolios. Al- 
though information on these portfolios is not included, these institutional portfolios share the basic strategy in terms of equity investments. The fund data used thus proxies the full spectrum of investment strategies in European equities pursued by the company.

The daily information we use includes all trades undertaken within the funds, all fund investment positions, and net money flows into or out of these funds. We also obtained basic fund information such as the ID of the fund manager, the fund benchmark relevant for fund manager evaluation as well as changes in any of this information during the sample period. We supplement this data with daily fund prices and benchmark returns.

Averaged over funds and days, we observe portfolios consisting of 58 different stocks and an average of 4.5 trades on any day that funds trade at least one stock. As our data comes from a large asset management firm, the sample funds' size is also large, relative to other funds. Table 1 provides information collected from Morningstar on the positioning of the sample funds relative to the set of funds belonging to their respective fund category. ${ }^{3}$ As can be seen from the assets under management, seven of our sample funds are in the top two quintiles of their respective fund category. Similarly, the management costs of the sample funds are also mostly in the upper quintiles. On the other hand, within their categories, our sample funds are quite diverse in terms of their investments with regard to firm size (all funds are generally classified as large-cap funds). In terms of their performance within their fund categories, our sample funds show some diversity, with more funds in the lower percentiles than in the upper percentiles. Parts of this performance structure could be explained by the generally larger fund size as well as the higher management costs (see e.g. Berk and Green, 2004; Chen, Hong, Huang, and Kubik, 2004).

Analyst recommendations: Internal stock recommendations originate from two groups of analysts, research analysts and small cap fund managers. The main task of the latter group is to manage small cap equity portfolios but they also give stock recommendations for a subset of the stocks they invest in. Research analysts are sector specialists who follow stocks in the sector of their expertise. These analysts very much resemble SSAs and sometimes worked for the sell-side previously or move to the sell-side later on. The job of a research analyst in our sample firm has a career path of its own. These analysts are hence

\footnotetext{
${ }^{3}$ Morningstar classifies funds according to their investment focus and style. These fund categories include, for example, Europe Large-Cap Blend Equity, Europe Large-Cap Growth Equity, or Eurozone Large-Cap Equity. The information was collected in October 2008 and was only available for 13 of our 14 sample funds as one sample fund was closed during the year 2007.
} 
no junior analysts who will be fund managers in the future. Although a few analysts also manage sector portfolios, their role as analyst is never secondary. Stock recommendations are analysts' key output and a major determinant for analysts' performance evaluation and hence remuneration. Another task of the research analysts is to discuss their views and industry/company news with fund managers. Although research analysts have their own company models, unlike SSAs they are not required to provide earnings estimates on a regular basis.

We use information on recommendations for European stocks issued by all internal research analysts (rather than small cap fund managers for whom recommendations are not the main aspect of their job). This implies that stocks analyzed are predominantly larger cap stocks, but this is also true for the stocks our sample mutual funds invest in. The daily information contains the stock, an analyst ID, and the current recommendation. Analyst stock recommendations are coded 1 for "sell", 2 for "underperform", 3 for "hold", 4 for "buy", and 5 for "strong buy". Changes in recommendations are recorded in the data set for the same day as the analyst announces the change if this occurs before the market opens. Else, they are recorded as of the subsequent trading day. These timing conventions are also used in the internal evaluation of the analysts.

For each stock traded by one of the sample funds, we collect SSA recommendations from the Thomson Reuters I/B/E/S database. These recommendations are originally coded in the opposite direction of the buy-side recommendations (from 1 for "strong buy" to 5 for "sell") and are recoded by us to match the buy-side structure. A higher recommendation in our data thus implies a more favorable view of the stock for both BSAs and SSAs. We use the daily mean consensus recommendation for each stock as well as I/B/E/S detail information for individual analysts' recommendations.

As the market consensus in many stocks is determined by a large number of SSAs, professional investors may decide not to pay attention to all recommendation revisions issued. Rather, some SSAs or brokerage firms might be followed more closely than others. We consequently also consider a sub-set of sell-side firms by identifying the key brokerage firms for our sample firm. We measure the relevance of a sell-side firm for our sample firm by the overlap between the stocks traded by the mutual funds and stocks covered by the sell-side firm. Hence, sell-side brokers which cover a higher number of stocks that were also traded by our sample funds are deemed more important. We rank all brokers covered in the I/B/E/S detail database and consider only the top 10 brokers in this ranking. 
Analysts employed by these 10 brokers will be termed key $S S A s .{ }^{4}$ Recommendation levels and revisions (excluding recommendation reiterations) by key SSAs are then used in the analysis.

Table 2 presents some information about the structure of BSA recommendations and contrasts it with key SSAs' recommendations. The table shows the distribution of recommendations, the mean recommendation as well as the number of recommendations issued and analysts employed over the sample period 2004 to 2007. For key SSAs, the figures are first aggregated at the level of the sell-side firm, and then averaged separately for firms ranked 1 to 5 as well as firms ranked 6 to 10 in terms of coverage overlap. Only stocks actually held by the mutual funds during the sample period are included in the table, with the final row providing the (average) number of stocks used. Even with this restricted set of stocks, the table shows that the key sell-side firms cover more stocks, employ more analysts, and issue more recommendations than the buy-side firm's analysts, as seems typical for the industry (Groysberg et al., 2008, 2013).

Differences in the distribution of recommendations between BSAs and key SSAs, on the other hand, are not very pronounced, with very similar mean recommendations or proportions of neutral recommendation. Comparisons of the distribution of votes is complicated by the fact that some sell-side firms do not use the full spectrum of recommendation levels. For example, one of the key sell-side firms does not employ hold recommendations, whereas others might not use the extreme recommendations sell or strong buy. This does not affect our subsequent analyses as we later only consider the direction of recommendation changes (revisions) by key SSAs, rather than the recommendation levels.

Earnings estimates: Although the consensus recommendation is an easily observable and hence prominent indicator, professional investors might consider alternative investment signals to be more important, not least because SSAs may provide biased investment recommendations (see Malmendier and Shanthikumar, 2007, 2013). We therefore also include I/B/E/S information about SSAs' earnings estimates. Specifically, we calculate earnings revisions as the relative change in the consensus earnings estimate over a specified period. In order to have a rolling measure of the consensus earnings, we use a timeweighted average of the earnings estimates for FY1 and FY2. The weighting factor for the

\footnotetext{
${ }^{4}$ We also considered different sets of key SSAs by including the top 3, 5 or 20 sell-side firms. Our results and conclusions are robust to these variations. In section 4.3, we also analyze the impact of a set of SSAs selected based on reputation rather than coverage.
} 
FY1 estimate is the number of trading days until the reporting date of the FY1 earnings relative to the number of trading days between the reporting days for FY1 and FY2. The weighting factor for FY2 is then 1 minus the factor for FY1. ${ }^{5}$ By this weighting structure, FY1 estimates receive a lower weighting the closer the corresponding reporting date.

\subsection{Transaction analysis sample}

Our main analysis on the trading impact of BSAs is a logit regression of the sign of a transaction on a set of internal and external variables. For this analysis, we match daily trades at the stock/fund level with buy-side recommendations and fund cash flows as internal variables, and with sell-side information (consensus recommendations and earnings as well as key SSA revisions) and stock returns as external variables. Table 3 provides descriptive statistics for the transactions sample, and Table 4 presents within-sample correlations. In a subsequent analysis, we will also look at the impact of the same set of external variables on the sign of BSA revisions.

The dependent variable in the trading analysis, Buy transaction, , is an indicator variable which takes on a value of 1 if a transaction is a buy and a value of 0 for a sell transaction, with $t$ being the day of the transactions. All independent variables are defined relative to this day, where level variables are measured on the same day while dynamic variables (changes or flows) are included for several, non-overlapping time periods. For example,

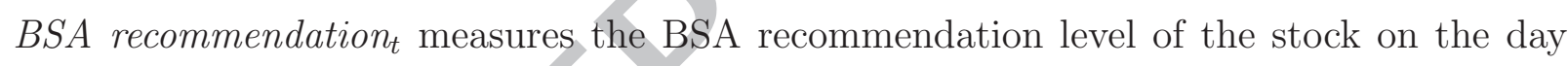
of the transaction. ${ }^{6}$ BSA recommendation revision $n_{t+1, t-1}$ is a signed indicator variable which takes on values of $-1,0$, or 1 if the BSA recommendation has been, respectively, lowered, unchanged, or increased in the period of one day prior to one day after the transaction. ${ }^{7}$ We similarly consider revisions during the remainder of the preceding week

\footnotetext{
${ }^{5}$ In case one of the FY estimates is missing, the available earnings forecast receives a weight of 1 . In addition, as firms' reporting dates might change over time, we restrict weights to be within the interval $[0,1]$.

${ }^{6}$ We note that the mean BSA recommendation in Table 3 is slightly higher than the mean BSA recommendation in Table 2. The two values differ as Table 3 reports the mean recommendation for every stock transaction, while the mean in Table 2 refers to all unique recommendations issued by BSAs.

7 We include the day after the transactions in order to account for fund managers receiving information about planned revisions by the BSAs. Limiting this variable to prior and same-day revisions does not affect our results qualitatively. We also disregard the level of recommendation revisions, as over $90 \%$ of revisions are single-level changes. Unreported regressions using information about the level of recommendation changes do not yield further distinctive effects.
} 
(BSA recommendation revision ${ }_{t-2, t-5}$ ) and changes that happened up to a month earlier $\left(B S A\right.$ recommendation revision $\left.{ }_{t-6, t-20}\right){ }^{8}$

Cash flows are measured in percentage relative to a fund's daily assets under management. We calculate the sum of cash flows over a set of days, differentiating by whether they were reported on the same or previous day as the trade (Cash Flowt,t-1) or during the remainder of the preceding trading week (Cash Flowt-2,t-5). Since cash flows have a very immediate effect on the portfolio structure, we do not consider cash flows which occurred over a week ago.

Among the external variables, recommendation revisions by key SSAs are defined very similarly to BSA revisions: Key SSA recommendation revision $n_{t, t-1}$ is a signed indicator with values -1 or 1 if an analyst by one of the key sell-side firms downgrades or, respectively, upgrades the stock on the day of or one day prior to the transaction, and with value 0 else. As with BSA revisions, we consider key SSA revisions during the remainder of the preceding week and the remainder of the preceding month. ${ }^{9}$

For consensus variables (recommendations and earnings) and returns, we allow for a potentially longer lag for them to affect transactions. Consensus recommendations are included both with the level on the trading day (Cons. recommendation $)_{t}$ ) and with the changes therein over three sub-periods: for the week prior to the transaction (from $t-5$ to $t$ ), for the remainder of the preceding month (from $t-20$ to $t-6$ ), as well as for months two to six (from $t-120$ to $t-21$ ) before the transaction. ${ }^{10}$ The same three sub-periods are used for earnings revisions (variables denoted Cons. earnings revision). These are measured as the percentage change in the weighted earnings forecast, calculated as the change in the forecast relative to the absolute value of the forecast, thus taking into account potentially negative earnings forecasts. We also winsorize the earnings revision variable to $\pm 100 \%$ in order to remove extreme values arising from earnings close to zero. ${ }^{11}$

\footnotetext{
${ }^{8}$ We denote 5 trading days as one week, and 20 trading days as one month.

${ }^{9}$ In case of more than one key SSA revising their recommendation during any of these periods, we use the sign of the difference between the number of upgrades and downgrades.

${ }^{10}$ Including both key SSA revision indicators as well as overall consensus revisions over the week and month preceding the transactions potentially gives rise to collinearity issues (we are grateful to a reviewer for pointing this out). While there exists a positive correlation between the variables (as can be seen from Table 4), the correlation coefficients are not overly high (the maximum correlation is 0.19). To ensure robustness of our results, we have repeated our analyses by deriving a key SSA consensus (and changes therein) from the I/B/E/S detail files and adjusting the consensus variables to exclude those key SSA recommendations. The (unreported) results are comparable to the results presented in the paper.

${ }^{11}$ Winsorizing the three earnings revisions variables at their respective 1 st and 99 th percentiles yields
} 
We include past return information over periods very similar to the consensus variables, with the only difference being that the prior week return $\left(\operatorname{Return}_{t-1, t-5}\right)$ uses the percentage change in closing prices until the day before the transactions, whereas the consensus variables include changes occurring on the transaction day. We thus assume that recommendation or earnings revisions are available already during the trading day, while closing prices, by definition, are not. ${ }^{12}$

\section{Transaction impact}

In this section, we consider the impact of BSA and SSA recommendations on the trading behavior of fund managers. In the first step, we look at the structure of transactions around buy-side recommendation changes. We then turn to a more thorough analysis of the determinants of trading decisions and BSA revisions.

\subsection{Recommendations and the structure of transactions}

If BSA recommendations matter for fund managers' investment decisions, we should expect to see changes in their behavior when recommendations are changed. Over the sample period, we observe 668 recommendation changes. Table 5 (Panel A) presents the distribution of these revisions in a transition matrix. The table shows the distribution of new recommendations by the prior recommendation level. The last column in Panel A gives the percentage of recommendation revisions by the prior recommendation level. ${ }^{13}$ Recommendation reiterations are not recorded for the buy-side analysts in the sample. Hence, the main diagonal of the transition matrix is empty.

The numbers in Panel A show that most of the recommendations by buy-side analysts are either a hold (recommendation of 3) or a buy (recommendation of 4). Over $76 \%$ of recommendation revisions start at these levels, and the transitions are also mostly towards these levels. Only very few recommendations originate from or target the lowest recom-

very similar results.

${ }^{12}$ Excluding same-day recommendation and earnings revisions does not materially affect our results.

${ }^{13}$ We note that the distribution in the final column of Table 5, Panel A, slightly differs from the distribution of BSA recommendations presented in Table 2. The difference arises because Table 2 reports the distribution of all recommendations, whereas the distribution in Table 5 captures all recommendations that are subsequently revised. Hence, the final recommendation levels for each stock are missing in the distribution shown in Table 5. 
mendation level. Additionally, the transition matrix shows that most recommendation revisions are single level changes. In later analyses, we will therefore neglect the size of recommendation changes and simply differentiate between upgrades and downgrades.

Panel B of Table 5 illustrates the distribution of buy versus sell transactions in stocks when these stocks' recommendations change. Specifically, the table reports the proportion of buy transactions among all transactions in a stock within the period starting one trading day prior to the recommendation change and ending one trading day afterwards. These buy proportions are averaged and presented for the same recommendation transitions as in Panel A. The results show that upgrades (numbers above the main diagonal) and downgrades (numbers below the main diagonal) go along with very different trading behavior: Upgrades are accompanied mostly by buy transactions, whereas sell transactions dominate for recommendation downgrades. As an example, consider an initial hold recommendation (level of 3 ). For the $65.3 \%$ of stock upgrades to a buy recommendation (recommendation level 4, see Panel A), buy transactions make up $87.1 \%$ of all transactions in these stocks in the three days period around the recommendation change. Conversely, for the $33.6 \%$ of stocks downgraded to underperform (recommendation level 2), 83.1\% (100\%-16.9\%) of transactions are sells. The results in Panel B show a strong congruence between fund managers' trading decisions and buy-side recommendation revisions.

Figures 1 and 2 provide further evidence of the impact of BSA revisions on fund manager trading. Both figures analyze trades in stocks around recommendation revisions. The event (revision) day is $\mathrm{t}=0$. Similarly to Panel B of Table 5, Figure 1 reports the proportion of buys (in percentages) up to five weeks prior to and after the revision. The dark-shaded bars show proportions of buys around upgrades, the light-shaded bars show buy proportions around downgrades. Figure 2 looks at the trading intensity of fund managers around recommendation revisions. It shows the average number of trades observed in a stock around its revision day, again for upgrades (dark-shaded bars) and downgrades (lightshaded bars) separately. In both figures, numbers are averaged on a daily basis for the first week around revisions. For weeks -5 to -2 and 2 to 5 , the figure reports weekly averages. ${ }^{14}$ Additionally, the dashed line in each figure represents the average during weeks -5 to -2 for both upgrades and downgrades.

Figure 1 shows that the congruence between recommendation revisions and fund managers' trades extends over a fairly long period. Recommendation upgrades (downgrades)

\footnotetext{
${ }^{14}$ The difference between weekly and daily averages is also highlighted in the figure by different background shading.
} 
shift post-revision trades towards buys (sells) for at least three weeks, with weakening effect over time: The difference between the proportion of buys after upgrades versus downgrades on revision days is over 80 percentage points and declines to roughly 25 percentage points three weeks afterwards. Trading activity also increases around recommendation revisions, as Figure 2 illustrates. On the revision days, average activity is almost five times higher than the average activity in weeks -5 to -2 prior to revisions. However, the effect appears not to be long-lasting as it vanishes within the first week following a revision. Both figures strongly highlight the impact of BSAs' recommendations on fund manager behavior.

A notable feature in Figures 1 and 2 is that the structure of transactions already changes in the days prior to recommendation revisions. This is not surprising for trades happening one to two days ahead of a revision: By the timing convention, a revision during trading hours results in a lag of one day between the day a revision is known internally and the formally recorded revision day. Additionally, analysts regularly communicate their planned revisions to fund managers. Updating their valuation models and writing an accompanying research report might then delay the officially recorded announcement by another day. These effects can best be seen in Figure 2 as the pick-up in trading activity is evident two days ahead of the revision day. Figure 1, however, shows that the distribution of buys and sells changes strongly even four days ahead of the revision. This pre-revision effect is unlikely to be due to time lags between an analyst's decision to revise a recommendation and the official announcement. Rather, it is due to other interactions between fund managers and BSAs. In particular, fund managers and BSAs share and discuss their views about stocks. These discussions can be around specific events, such as company meetings, company announcements, or institutionalized meetings between analysts and fund managers. This may enable analysts to give an early indication of their plans to revise a recommendation or may allow fund managers to correctly assess the direction of the next revision. Alternatively, fund managers might be able to convince analysts to revise recommendations while simply trading according to their own views. Although it is not discernible from the data which mechanism drives the pre-revision effects, conversations with fund managers and analysts suggest that revisions determine fund managers' transactions rather than vice versa. 


\subsection{Explaining the direction of trades}

The previous analysis suggests that buy-side recommendations have a strong effect on whether fund managers buy or sell a specific stock. Therefore, we look at this decision in more detail. We first show that BSA recommendation revisions and fund flows have a high impact on the trade direction even after controlling for other investment signals and control variables. We then analyze whether BSA recommendations are more than a compound signal of the set of public investment signals.

Table 6 presents the results of a logit regression of buys versus sells on various internal and publicly observable variables. The dependent variable takes on a value of 1 if a stock transaction by a single mutual fund during a day is a buy transaction and 0 if the transaction is a sell. The explanatory variables include the internal information about BSA recommendations (both current levels and past changes) and cash flow information. For the publicly observable investment signals, we use consensus recommendations and earnings estimates. We use the current levels of the consensus recommendation as well as the value of past changes therein, distinguishing between three sub-periods within the preceding six months to account for how recent the changes in the variable are. For the consensus earnings estimates, we consider percentage changes over the same sub-periods as for recommendations. The consensus variables provide a signal of the average analyst's recommended transaction and should take into account all relevant stock information up to the day of transaction. In addition, we use recommendation revisions by key SSAs for three sub-periods within the preceding month. We also include past stock returns as a control variable. This variable captures potential momentum or contrarian trading by the fund managers.

The results of the logit analysis show that all internal variables are highly statistically significant whereas only some of the public investment signals determine trading decisions. Recommendation upgrades (downgrades) by either the buy-side or the sell-side (consensus or key brokers) positively (negatively) affect the propensity to buy a stock for all time periods between the revision and the transaction considered here. The effects of key SSA revisions are statistically highly significant for the more recent recommendation revisions and decline over time. For consensus recommendations, only those changes that occur more than a week prior to a transaction are statistically significant. Hence, the key SSAs have a very immediate effect, whereas changes in the consensus matter only with some lag but do so for a long period of time. Cash inflows also increase the probability of a buy transaction. 
This is as expected as fund managers usually prefer to hold only small cash positions. The inflow of new money thus triggers at least some buy transactions. Recommendation levels show less clear results. While they increase the propensity to buy when issued by BSAs, higher consensus recommendation levels have an insignificant (and marginally negative) effect. This is consistent with fund managers considering recommendation changes to contain investment value whereas the level of a recommendation is less relevant. Similar to recommendation levels, past stock returns show no consistent effects. While the most recent returns positively affect the propensity to buy, less recent returns have the reverse effect. Consensus earnings revisions have only weak effects (if any at all) on the sign of transactions, again with no consistent direction.

The last columns of Table 6 report the average marginal effects of changes in the explanatory variables. The results show that the internal signals have the highest economic impact on trade directions. Most notably, a BSA's recommendation upgrade (downgrade) on the following, same, or previous day increases (decreases) the probability that fund managers buy that stock by almost 43 percentage points. Although the effect decreases over time it is still economically high (close to 16 percentage points) if the revision happened between two to four weeks before the transaction. As a comparison, the maximum effect that a similar change in the consensus recommendation has is 19.4 percentage points. Although it generally depends on the coverage of a stock, a one-unit change in the consensus within a single week is highly unlikely. The effect of a two standard deviations change in the consensus is about 3.7 percentage points $(0.194 \times 2 \times 0.096)$. Nevertheless, the sell-side information signal has an impact that persists even for periods of up to six months. Key SSAs have a very immediate impact: A revision on the same or the preceding day shifts the likelihood of a buy transaction by 7.1 percentage points. A cash flow of one percent of a fund's asset value over the same or previous trading day changes the buy probability by 16 percentage points in the same direction. The effect is reduced to 4.8 percentage points if the cash flow occurs 5 to 3 days before the trading date. Finally, past returns and recommendation levels, although statistically significant, show low economic impact on trade directions.

In order to further illustrate the effect of buy-side analysts' revisions, we allow for differences in the effects of upgrades and downgrades. For this analysis, we repeat the above logit analysis, but replace the original BSA recommendation revision variables with separate (positive) indicators for upgrades (versus no revision or a downgrade) and for downgrades (versus no revision or an upgrade) occurring within the respective time periods. 
We present the results for these new indicators in Panel A of Table 7, thereby omitting the results for the other explanatory variables used, as the results for these other variables are only minimally different to those in Table 6.

Both, BSA upgrades and downgrades affect the direction of trades significantly, with opposite directions. Two particular patterns emerge from the separation of upgrades and downgrades. First, the marginal effects of upgrades are generally higher (in absolute terms) than those of downgrades, given the same time period. Second, while the effect of upgrades is more immediate, the effect of downgrades appears to be more persistent. For downgrades, the effect remains almost constant over the week preceding the transaction, and the decline in the effect for the period of four to one weeks before the transaction is also less pronounced than for upgrades. Overall, while the effect of upgrades and downgrades on transactions is slightly different, we can still confirm that, irrespective of direction, BSA revisions are key determinants of fund managers' trading decisions.

\subsection{The direction of buy-side analysts' revisions}

In order to gauge whether BSA recommendation revisions are more than a combination of the public investment signals considered by fund managers, we now turn to the recommendation upgrade or downgrade decision. Similar to the trade direction analysis, we perform a logit regression of the direction of the stock recommendation revisions. The dependent variable thus takes on a value of 1 (0) if the analyst upgrades (downgrades) the stock. For the independent variables, we use the set of publicly observable variables (consensus and key SSA recommendations, consensus earnings and returns) as in the analysis of trade directions.

The results and average marginal effects of the logit analysis are presented in Table 8. Only few variables turn out to be statistically significant (at the $10 \%$ level). The most important variable in the analysis are the revisions by key SSAs. In comparison to the transaction analysis, revisions by these key analysts relate to BSAs' revisions more strongly when happening almost at the same time: A recommendation upgrade by key SSAs increases the likelihood that a BSA revision is an upgrade by 28.3 percentage points if it happens on the same or previous day. If the sell-side upgrade happens up to a week ago, the effect is only weakly significant with a marginal effect of 11.6 percentage points, and is insignificant for longer periods. In contrast to the key SSAs, consensus recommendations are not statistically significant. However, consensus earnings revisions have some, albeit 
limited, positive impact on the direction of BSA revisions. Finally, stock returns over the prior week have a marginally significant effect. However, the overall effects of past returns are rather inconclusive as their direction changes over longer-term periods.

Based on the above effects of external investment signals on BSA revisions, we analyze whether these revisions still affect transactions once the external variables have been taken into account. For this, we create a BSA recommendation surprise variable, calculated as the dependent variable in the logit of BSA revisions minus the predicted probability of an upgrade derived from that model. We thus weigh any revision occurring by one minus the expected probability of that revision, taking into account the direction of the revision. For example, if the predicted probability of a revision being an upgrade is $60 \%$, then the surprise if the revision is indeed an upgrade is $40 \%(1-0.6)$, whereas if it is actually a downgrade, then the surprise variable is $-60 \%(0-0.6)$. We then repeat the earlier logit analysis of transactions signs, replacing the BSA recommendation revision variables with the surprise variable whenever a revision occurred within the relevant time period; absent such a revision, the surprise variable is set to zero.

Panel B of Table 7 presents the results of the logit analysis of transaction signs on the surprise part of a BSA revision. As in Panel A, we only report the results for the new BSA suprise variables. The underlying analysis still includes the same set of other explanatory variables as in Table 6, and the effects of these other variables are qualitatively unchanged. The results show a statistically and economically significant effect of the surprise component of BSA revisions, again with a declining effect over time. Hence, even after accounting for the part of a revision that could have been expected given public information, BSA revisions continue to have a strong impact on trading decisions.

In sum, our results suggest that BSAs' recommendation revisions play an important role as internal investment signals. Their impact is also larger than that of the sell-side consensus. And even though BSAs and fund managers might partly follow similar investment signals, the recommendation revisions by BSAs can be shown to have additional information content for the fund managers.

\section{Performance impact}

The previous results show that BSA and, to a lesser extent, key SSA recommendations affect trading decisions. We now consider the impact of analyst recommendations on fund performance. Before analyzing the performance of fund transactions, we first consider the 
performance of BSAs' and key SSAs' revisions. In the following, we restrict our sample to those stocks that were covered by the BSAs at some time (i.e. where there is at least one BSA recommendation) during January 2004 and December 2007. As a consequence, when comparing the performance (and performance impact) of BSAs and key SSAs, we control for a potential selection effect due to differences in coverage between the buy-side and the sell-side (see Groysberg et al., 2013).

\subsection{The performance of analysts' recommendation revisions}

We measure BSA performance by calculating the percentage return of each stock upgrade and downgrade for holding periods of one, five, 10, 15, 20, 40, 60 and 120 trading days as of the day of the recommendation change. We report both raw returns as well as abnormal returns. A stock's abnormal return is computed as the difference between the raw return and the stock's expected return. Expected returns are the result of a regression of daily stock returns on an intercept and the market return during the sample period. We use the MSCI Europe index for the market return. Returns are averaged for all upgrades and downgrades with equal weighting.

Table 9 presents the performance of BSA revisions as well as the difference in performance between upgrades and downgrades. Looking at raw returns, Panel A shows that stocks that have been upgraded have almost steadily increasing performance over time. Even the returns to downgraded stocks turn positive and increase over time. The general increase in stock prices is not overly surprising, given the time period of our analysis. However, the results also show that the return difference between recommendation upgrades and downgrades is positive for all holding periods, and statistically significant for the first two months. This return difference builds up from 0.5 to 1.0 percentage points over the first week and reaches a maximum of 2.5 percentage points after one month. A similar structure of return differences is also visible in abnormal returns (Panel B). The difference in abnormal returns between upgrades and downgrades increases from 0.56 to 2.01 percentage points within one month and decreases thereafter. Overall, BSA revisions contain investment value which, statistically, can be confirmed for holding periods of one to two months.

We next consider the performance of the top 10 brokers' analyst recommendation revisions. The logit analysis shows that very recent revisions by key SSAs positively affect fund manager transactions, even though the effect is much weaker than for BSAs. Simi- 
larly to the analysis in Table 9, we calculate percentage returns of each stock upgraded and downgraded by key SSAs for the various holding periods. ${ }^{15}$ Again, we measure the analyst return based on the closing price on the revision day. This implies that we disregard the potential announcement day effect that has been found for SSA revisions (see Francis and Soffer, 1997; Ivkovic and Jegadeesh, 2004). Although we thus miss out a part of the stock return generally attributed to a revision, this lag in the performance calculation is more relevant for fund managers as they are usually not able to react fast enough to realize the announcement day return.

Table 10 presents the performance of key SSA upgrades and downgrades, the difference in performance between these two revisions, as well as the difference in returns to revisions by BSAs versus key SSAs in the last column pair. ${ }^{16}$ The results show that the key SSAs also provide valuable investment recommendations. Both upgrades and downgrades show statistically significant positive and negative abnormal returns, respectively, over almost all holding periods. Moreover, the return differences are statistically significant over all holding periods.

For both BSAs and key SSAs revisions, overall returns are positive and significant over at least one month. The comparison of the two groups in the last column pair of Table 10 shows that the returns (that is, the difference in returns between upgrades and downgrades) to BSA revisions are on average higher than the returns to key SSA revisions, both in terms of raw and abnormal returns. This result is statistically significant for holding periods of 2 weeks to one month.

The fact that key SSA recommendations perform worse than those of BSAs might at first appear surprising: Typically, the sell-side would be expected to provide superior services, given the strong incentives of higher pay, stricter performance evaluation, and tougher job retention criteria at the sell-side (see Groysberg et al., 2008). However, Groysberg et al. (2013) show that when restricting the analysis on stocks covered by both the buy-side and the sell-side, the superior performance of SSAs' buy recommendations vanishes. In our analysis, we also focus on jointly covered stocks, and in addition to that consider the performance contribution of both upgrades and downgrades. Adding the latter adds further to the performance difference between BSAs and key SSAs.

\footnotetext{
${ }^{15}$ If there are multiple revisions on a day, the difference between the number of upgrades and downgrades determines the revision direction; an equal number of upgrades and downgrades is interpreted as no revision.

${ }^{16}$ We refer to the columns of returns and associated t-statistics as column pairs.
} 
Another important aspect of our analysis is that we focus on only a subset of the sellside. Given our interest on the impact of analysts on trading behavior and the performance of trades (analyzed next), we select the key SSAs by their relevance for the sample funds, measured in terms of coverage. This choice of sell-side firms might neglect other, more capable SSAs. We will revisit this issue by analyzing the impact of a more quality-based selection criterium on analyst performance and performance impact in section 4.3.

\subsection{Performance of fund managers' transactions}

Given that BSAs and key SSAs generate valuable investment signals and that fund managers appear to trade consistently with these signals, we should expect to see positive performance of trades induced by these revisions. We now analyze fund managers' transactions and consider the returns to buy and sell transactions as well as return differences.

Tables 11 presents the performance of buy and sell transactions for three sub-samples of fund transactions. The first sample (in column pairs one and four) contains all transactions where a recommendation revision by a BSA is observed in the period of one trading day prior to one trading day after the transaction. From the analysis in section 3 , we know that these transactions are very likely to be driven by the internal investment signal. The second set of trades (in column pairs two and five) consists of transactions for which a revision by the set of key SSAs is observed on the day of trading or the previous day. ${ }^{17}$ The final transaction sample contains all trades which were not attributed to any of the previous samples. This sample thus contains transactions that are not (solely) driven by BSA nor key SSA recommendations but are possibly based on other information. We look at raw (Panel A) and abnormal returns (Panel B) over the same time-horizons as in Tables 9 and 10. Although the funds in our sample have different, fund-specific benchmarks (given their differences in investment focus and style), we continue using the MSCI Europe index as the market return. Unreported calculations using market-adjusted returns with fund-specific benchmarks yield very similar results.

The results for the raw returns show again positive returns for both buys and sells over the longer return periods. In addition, raw returns to buys are - with few exceptions positive and increasing in holding periods. Sell transactions triggered by BSA or key SSA

\footnotetext{
${ }^{17}$ There is a set of 104 transaction for which both BSA and key SSA revisions jointly occur within the relevant time period. In the tables reported, these transactions are retained in both transaction samples. Omitting them from both samples marginally lowers the average transaction returns, but leaves our overall return comparisons and conclusions unaffected.
} 
revisions produce negative returns during the first month and then turn positive. Abnormal returns, however, show a rather different picture: Buy transactions triggered by BSAs or key SSAs show hardly any statistically significant returns, while the other buy transactions produce statistically significant and positive returns over a period of two months. Sell transactions, on the other hand, produce statistically significant negative abnormal returns over almost all holding periods for all three transaction samples. Moreover, abnormal returns to sell transactions following analyst revisions are rather sizable with below $-2.5 \%$ over the six month holding period. These results suggest that, when acting on analyst revisions, our sample firm's fund managers are particularly good in identifying profitable selling opportunities, and rather weak in identifying profitable buying opportunities.

Table 12 analyzes return differences between buy and sell transactions for our three samples, focusing on the differences in abnormal returns. ${ }^{18}$ In Panel A, the first three column pairs present the absolute return differences for the sample of BSA induced trades, key SSA induced trades, and all other trades, respectively. The results show that return differences to BSA induced trades as well as other trades are positive and statistically significant for holding periods of up to two months. For trades around key SSA revisions, returns are also positive, but statistically significant only for holding periods of up to one month.

While all transaction samples show positive return differences between buys and sells, our results also suggest that transactions following BSA revisions provide higher returns than trades from any of the other two samples. The fourth column pair in Panel A of Table 12 compares return differences for trades triggered by BSAs versus key SSAs, and the last column pair compares BSA induced trades with the sample of all other trades. In both comparisons, the return differences to BSA induced trades are positive. The differences in abnormal return differences between the BSA and key SSA induced samples is statistically significant for holding periods of up to two weeks. When compared with all other trades, BSA induced trades provide statistically significant superior abnormal returns for all holding periods considered. These comparisons show that the performance impact of BSAs to fund performance, alongside the earlier trading impact, is positive. In addition, the higher performance of BSA revisions relative to key SSA revisions recorded earlier appears to induce a performance impact on transactions that is also slightly higher for BSAs than for key SSAs. We will later analyze whether this result is robust to an

\footnotetext{
${ }^{18}$ The results from looking at differences in raw returns are very similar and therefore not presented here.
} 
alternative selection of sell-side firms.

Panel B of Table 12 provides some further information on the source of the performance impact of BSAs and key SSAs to fund performance. In this analysis, we split the two sets of analyst induced trades by whether the transactions actually follow the analyst revision (congruent trades, column pairs one and two) or go against the revision (contrarian trades, column pairs three and four). The table then reports the difference in abnormal returns between buys and sells for the four samples. As can be seen in the last row of Panel B, our fund managers follow key SSAs more often than not, but a large proportion of trades still is contrary to the revisions. On the other hand, only relatively few transactions go against BSA revisions, again illustrating the high impact of these revisions. Looking at the performance of trades shows that trading against analyst revisions does not produce positive returns. Rather, the performance to contrarian trades over the shorter term (one to three weeks) is significantly negative and insignificant thereafter. On the other hand, returns to congruent trades produce high positive returns which are statistically significant for holding periods of up to two and three months for BSA induced and key SSA induced transactions, respectively. Hence, while analyst revisions are valuable input to the sample fund managers, these managers do not show specific abilities in separating profitable and unprofitable revisions. This finding is similar to the finding in Busse et al. (2012) that US fund managers are unable to identify profitable and unprofitable SSA recommendations. Our results suggest that this pattern may even hold when considering revisions by internal analysts.

\subsection{Performance impact of highly ranked sell-side analysts}

Our results for both analyst revisions as well as transactions attributable to analyst revisions suggest that BSAs have a slightly more positive effect on returns than key SSAs, although the finding is only statistically significant for return periods of up to 1 month. One of the reasons for the results could be that by selecting key sell-side firms by their coverage, we are selecting a set of analysts with lower abilities. ${ }^{19}$ Fang and Yasuda (2013), for example, show that analyst abilities differ significantly, leading to sizable differences in returns to recommendations by analysts of high or low abilities. Moreover, the authors show that higher-ability analysts can be identified by their ranking in the yearly Institutional Investor magazine.

\footnotetext{
${ }^{19} \mathrm{We}$ are grateful for a reviewer for drawing our attention to this aspect.
} 
In order to analyze the effect of our selection of key SSAs, we repeat the performance analysis of sections 4.1 and 4.2 using a set of sell-side firms selected according to their industry ranking. Specifically, we select analysts from all sell-side firms that were ranked among the top 5 based on their overall research strength in the October issues of the Institutional Investor magazine in 2004, 2005, and 2006. As these rankings are relatively stable over time, we thus ended up with analysts from six different sell-side firms. ${ }^{20}$ Table 13 presents the results of our analyses.

Panel A of Table 13 reports the abnormal returns to SSA revisions and differences therein for the set of highly ranked SSAs, similar to Table 10, Panel B's presentation of the returns to key SSA revisions. The final column pair correspondingly compares the return differences between BSA and highly ranked SSA revisions. The results suggest that the new selection of SSA firms does not yield a performance improvement for SSA revisions. Rather, it appears that the selected set of analysts performs slightly worse than the key SSAs selected by coverage. This is particularly visible in the weak and even negative (although statistically insignificant) performance of upgrades.

Looking at the impact on transaction performance, on the other hand, suggests that following highly ranked SSAs more positively affects performance. Panel B of Table 13 presents abnormal return differences for the three transaction samples (BSA induced transactions, SSA induced transactions, and other transactions) when we consider the highly ranked set of sell-side firms. Comparing the return differences for transactions induced by highly ranked SSAs with those induced by key SSAs (as reported in Panel A of Table 12), we find that the return differences for highly ranked SSAs are all higher except for the 1-day return period, and remain statistically significant and positive over all return periods longer than one week. As a result, the performance differences between BSA and SSA driven transactions, albeit still positive, also decreases and is only significantly positive for BSAs for a period of up to one week.

Overall, our results suggests that the method of selecting the relevant set of SSAs

\footnotetext{
${ }^{20}$ As the firm rankings used are based on the performance of analysts in the US market, we implicitly assume that the reputation and ability of sell-side firms carry over into the European markets as well. We also repeated the analysis with the set of top 5 sell-side firms from the 2003 All-Europe Research Team ranking, published in the February 2003 Institutional Investor magazine. Three sell-side firms are represented in both sets of firms. Also, the results based on the European ranking are qualitatively the same as those presented here. As the 2003 All-Europe Research Team ranking was the only Europeanfocused ranking close to our sample period while the US rankings were more frequent and cover the entire sample period, we chose the latter rankings for the results presented.
} 
has an effect on analysts' performance and their performance impact on fund managers. Moreover, the above results also indicate that the impact on fund manager performance and the performance of SSA revisions might be affected differently by the selection of SSAs. On the other hand, our key result about the relevance of BSAs appears sufficiently robust to the choice of SSAs. These findings suggest that, generally, further research is warranted into the relationship between analysts' performance, ability, and their impact via active investors' decisions.

\section{Trading profits and the value of buy-side analysts}

Our results show that BSAs positively affect fund manager trading and the performance of their trades. However, the performance impact so far depends on the holding period considered. We now provide a more concrete, albeit rough, estimate of the value of BSAs for the asset management firm. To do so, we calculate realized trading profits for round-trip transactions that were likely to be initialized by BSAs. We select all transactions in stocks that had a same-directional revision in the period of one day prior to one day after the transaction. We then eliminate all transactions which afterwards had no offsetting trades by the same fund until the end of our sample period. For the remaining transactions, we calculate round-trip raw profits using reported execution prices. As an illustration, consider a BSA-induced buy of 100 shares in stock $X$ at a price of 1 at date 0 . The transaction is offset by sells at two distinct dates: 60 shares of $X$ are sold at a price of 2 at date 1 , and 40 shares are sold at a price of 1.5 at date 2 . The round-trip profit is hence 80 . The same profit results if 100 shares are sold at date 2 (the fund might have already had a position in $X$ at date 0 ) - only the sale of 40 shares is needed to close the position. Thus, offsetting transactions need not be contained in a single trade and might be part of an even larger trade. Also, subsequent transactions other than offsetting trades are disregarded until the position is closed: The trading profits in the example remain unaffected by additional purchases of $X$ between date 0 and date 2 . We thus assume that the BSA-induced transaction is always closed first.

We provide several adjustments to the raw profits generated by the round-trip transactions. Market-adjusted profits are derived by deducting the profits from equal-sized investments into the MSCI Europe index on the transaction day. Investment returns from this hypothetical portfolio are realized at the same point(s) in time as the stock investment. In order to account for the stock-specific risk, we also calculate beta-adjusted profits by 
adjusting the investment into the market index by the stock's beta. Finally, we derive profits when transactions are executed without transaction costs and net of transaction costs. Transaction costs for stocks are included in our data set, and we use transaction costs of 5 basis points for investments into the hypothetical index portfolio.

Table 14 presents the results for the profits from 349 round-trip transactions following BSA revisions. The average raw return before transaction costs amounts to about $€ 110,000$ or a total profit of $€ 38.4$ million during the 3.5 years of the sample. Transaction costs reduce this profit by almost $€ 4$ million. Adjusted profits are considerably lower, with beta-adjusted profits being at the lowest level. Net of transaction costs, beta-adjusted profits amount to $€ 4.5$ million a year.

As transaction profits at first accrue to mutual fund investors, we need an estimate for the profits these transactions generate for the asset management firm. For this, we assume that the trading profit generated in a year is invested in the market portfolio and yearly pays out management fees. Discounting the infinite stream of fee income yields a net present value for the asset management firm. Writing this net present value as a fraction of the one-period trading profit gives

$$
\frac{N P V_{B S A}}{\pi_{t}}=\sum_{t=0}^{\infty} f\left(\frac{(1-f)\left(1+r_{M}\right)}{1+r_{d}}\right)^{t}=\frac{f\left(1+r_{d}\right)}{r_{d}+f-r_{M}(1-f)}
$$

where $\pi_{t}$ denotes the trading profit, $f$ the management fee, $r_{M}$ the return on the market portfolio and $r_{d}$ the discount rate. Using the CAPM for the discount rate, we can write $r_{d}=r_{f}+\beta\left(r_{M}-r_{f}\right)$ with $r_{f}$ as the risk-free rate. The mutual funds in our sample charge management fees between $1.5 \%$ and $2.0 \%$ of assets. We use a risk-free rate of $3 \%$, an equity premium of $5.5 \%$ (see e.g. Dimson, Marsh, and Staunton, 2008) and a "financials" $\beta$ of 1.3. Running the numbers results in a net present value which is between $50.4 \%$ and $57.7 \%$ of the trading profit. ${ }^{21}$ Hence, the value of the buy-side analysts would be between $€ 2.27$ and $€ 2.60$ million per year.

During the sample period, the asset management firm employed between 18 and 23 research analyst at various experience levels. Assuming an average yearly cost per analyst of $€ 400,000$ (approximately US\$500,000 to 550,000) and employment of 20 analysts implies that the value of these analysts as derived above only amounts to $28 \%$ to $33 \%$ of their costs. By these estimates, the profits generated by BSAs would fall significantly

\footnotetext{
${ }^{21}$ Varying the risk-free rate between $2 \%$ and $4 \%$, the equity premium between $4 \%$ and $7 \%$ and $\beta$ between 1.1 and 1.5 results in a NPV range between $33 \%$ and $82 \%$ of trading profits.
} 
short of their costs. However, the value generation estimates should be interpreted as a lower bound to the value of BSAs, and are likely to be higher for various reasons. For example, not all transactions that are likely to be induced by BSAs are included in the profit calculation of Table 14. For some BSA-induced transactions there were no offsetting trades. Moreover, institutional portfolios managed by the same group of fund managers are not included in the data.

Another important reason why our estimate is likely to be too low arises from two potential revenue effects of BSAs. First, BSAs might induce further inflows: As investors prefer to invest into better-performing funds (see e.g. Ippolito, 1992; Chevalier and Ellison, 1997), fund returns enhanced by BSAs also yield higher inflows. Second, with BSAs adding to the performance of its mutual funds, the asset management firm might be able to charge higher management fees than it would be able to charge without BSAs. Depending on the competitive environment of the market for its mutual funds, this implies that the value created would be higher than just the additional fee income derived from the trading profit (see Luo, 2002, for both a theoretical model and empirical evidence for mark-up pricing by mutual funds). Under a less than perfectly competitive environment, a positive proportion of the trading profit would be skimmed off by the asset manager.

In sum, even though our simple estimate of the value of BSAs falls short of their costs, there are various reasons why we potentially underestimate the value of BSAs. However, in particular the indirect effects of BSAs on fund revenues on assets are hard to gauge. Hence, as the directly measurable value generated by BSAs appears too low, our results show that the value generation process in asset management remains an interesting and important research area.

\section{Conclusion}

Equity research analysts provide financial market information that can be sold in two ways, directly and indirectly (see Admati and Pfleiderer, 1988, 1990; Biais and Germain, 2002). Sell-side analysts are direct sellers of information whereas buy-side analysts and asset managers sell their information indirectly. In many asset management firms, the task of gathering and producing investment information and the task of making investment decisions are separated. Fund managers may hence rely on both information sources and decide for themselves on the use of the information. This paper analyzes how fund managers use private (buy-side) and public (sell-side) information by directly linking recommendations 
from both sources to transactions.

Our results show that fund managers react most strongly to recommendation changes by buy-side analysts. Jegadeesh et al. (2004) have already documented that the information content of sell-side stock recommendations is highest in recommendation changes. The response by fund managers suggests that the same is true for buy-side recommendations. Additionally, the private nature of buy-side recommendations probably ensures that prices will not (instantly) reflect the information. It is thus more profitable to respond to a signal if it is private. The higher impact of buy-side recommendations, particularly in comparison with the sell-side consensus, found in our analysis is consistent with this interpretation.

The analysis of the returns to buy-side analyst recommendations shows that following buy-side analysts' revisions can be profitable for fund managers. Transactions triggered by buy-side analyst revisions yield positive abnormal returns that exceed those of other transactions. In sum, the behavior of fund managers and the impact of buy-side analysts found in the analysis accords well with models of investment decisions and market microstructure under public and private information.

Since our data come from a single firm, our results are clearly not generally applicable to the overall asset management industry. However, our results show a consistency of the sample firm's business model of using sell-side information while at the same time employing buy-side analysts. As this is a widely adopted business model, our analysis can be of interest to other firms in the industry as well as fund investors. 


\section{References}

Admati, A. R. and P. Pfleiderer (1988). Selling and trading on information in financial markets. American Economic Review 78(2), 96-103.

Admati, A. R. and P. Pfleiderer (1990). Direct and indirect sale of information. Econometrica 58(4), 901-928.

Barber, B. M., R. Lehavy, M. McNichols, and B. Trueman (2001). Can investors profit from the prophets? Security analyst recommendations and stock returns. Journal of Finance 56(2), 531-563.

Barber, B. M., R. Lehavy, and B. Trueman (2007). Comparing the stock recommendation performance of investment banks and independent research firms. Journal of Financial Economics 85(2), 490-517.

Berk, J. B. and R. C. Green (2004). Mutual fund flows and performance in rational markets. Journal of Political Economy 112(6), 1269-1295.

Biais, B. and L. Germain (2002). Incentive-compatible contracts for the sale of information. Review of Financial Studies 15(4), 987-1003.

Boni, L. and K. L. Womack (2003). Wall Street research: Will new rules change its usefulness? Financial Analysts Journal 59(3), 25-29.

Boston Consulting Group (2007). The growth dilemma. Global asset management 2007.

Busse, J. A., T. C. Green, and N. Jegadeesh (2012). Buy-side trades and sell-side recommendations: Interactions and information content. Journal of Financial Markets 15(2), $207-232$.

Chen, J., H. Hong, M. Huang, and J. D. Kubik (2004). Does fund size erode mutual fund performance? the role of liquidity and organization. American Economic Review 94(5), 1276-1302.

Chen, Z. and W. J. J. Wilhelm $(2012,7)$. Sell-side information production in financial markets. Journal of Financial and Quantitative Analysis 47, 763-794. 
Cheng, Y., M. H. Liu, and J. Qian (2006). Buy-side Analysts, Sell-side Analysts, and Investment Decisions of Money Managers. Journal of Financial and Quantitative Analysis $41(1), 51-83$.

Chevalier, J. and G. Ellison (1997). Risk taking by mutual funds as a response to incentives. Journal of Political Economy 105(6), 1167-1200.

Dimson, E., P. Marsh, and M. Staunton (2008). The worldwide equity premium: A smaller puzzle. In R. Mehra (Ed.), Handbook of the Equity Risk Premium, pp. 467-514. Elsevier.

Fang, L. H. and A. Yasuda (2013). Are stars' opinions worth more? the relation between analyst reputation and recommendation values. Journal of Financial Services Research, forthcoming.

Francis, J. and L. Soffer (1997). The relative informativeness of analysts' stock recommendations and earnings forecast revisions. Journal of Accounting Research 35, 193-211.

Franck, A. and A. Kerl (2013). Analyst forecasts and European mutual fund trading. Journal of Banking \&3 Finance 37(8), 2677 - 2692.

Gray, W. R., S. Crawford, R. A. Price, and B. Johnson (2012). Do buy-side recommendations have investment value? SSRN eLibrary.

Grossman, S. J. and J. E. Stiglitz (1980). On the impossibility of informationally efficient markets. American Economic Review 70 (3), 393-408.

Groysberg, B., P. Healy, and C. Chapman (2008). Buy-side vs. sell-side analysts' earnings forecasts. Financial Analysts Journal 64(4), 25-39.

Groysberg, B., P. Healy, G. Serafeim, and D. Shanthikumar (2013). The stock selection and performance of buy-side analysts. Management Science 59(5), 1062-1075.

Ippolito, R. A. (1992). Consumer reaction to measures of poor quality: Evidence from the mutual fund industry. Journal of Law and Economics 35(1), 45-70.

Irvine, P. J. (2004). Analysts' forecasts and brokerage-firm trading. Accounting Review 79, $125-149$.

Ivkovic, Z. and N. Jegadeesh (2004). The timing and value of forecast and recommendation revisions. Journal of Financial Economics 73(3), 433-463. 
Jegadeesh, N., J. Kim, S. D. Krische, and C. M. C. Lee (2004). Analyzing the analysts: When do recommendations add value? The Journal of Finance 59(3), 1083-1124.

Kacperczyk, M. and A. Seru (2007). Fund manager use of public information: New evidence on managerial skills. Journal of Finance 62(2), 485-528.

Kyle, A. S. (1985). Continuous auctions and insider trading. Econometrica 53(6), 13151335 .

Kyle, A. S. (1989). Informed speculation with imperfect competition. Review of Economic Studies 56(3), 317-355.

Luo, G. Y. (2002). Mutual fund fee-setting, market structure and mark-ups. Economica $69(274), 245-271$.

Malmendier, U. and D. Shanthikumar (2007). Are small investors naive about incentives? Journal of Financial Economics 85(2), 457-489.

Malmendier, U. and D. Shanthikumar (2013). Do security analysts speak in two tongues? Review of Financial Studies, forthcoming.

Mokoaleli-Mokoteli, T., R. J. Taffler, and V. Agarwal (2009). Behavioural bias and conflicts of interest in analyst stock recommendations. Journal of Business Finance $\&$ Accounting 36(3-4), 384-418.

Pomorski, L. (2008). Acting on the most valuable information: 'Best idea' trades of mutual fund managers. SSRN eLibrary.

Tabb Group (2006). The future of equity research. A 360 degree perspective.

Womack, K. L. (1996). Do brokerage analysts' recommendations have investment value? Journal of Finance 51(1), 137-167. 
Figure 1: Percentage of buy transactions around BSA recommendation revisions

This figure reports the average proportion of buys (in percentages) in a stock around the day ( $\mathrm{t}=0$ ) a BSA revises the stock's recommendation. The dark-shaded bars show buy proportions around upgrades, the light-shaded bars show buy proportions around downgrades. Averages are taken on a daily basis for the first week around revisions (white background). For weeks -5 to -2 and 2 to 5 , the figure reports weekly averages (shaded background). The dashed line denotes the average for upgrades and downgrades over weeks -5 to -2 .

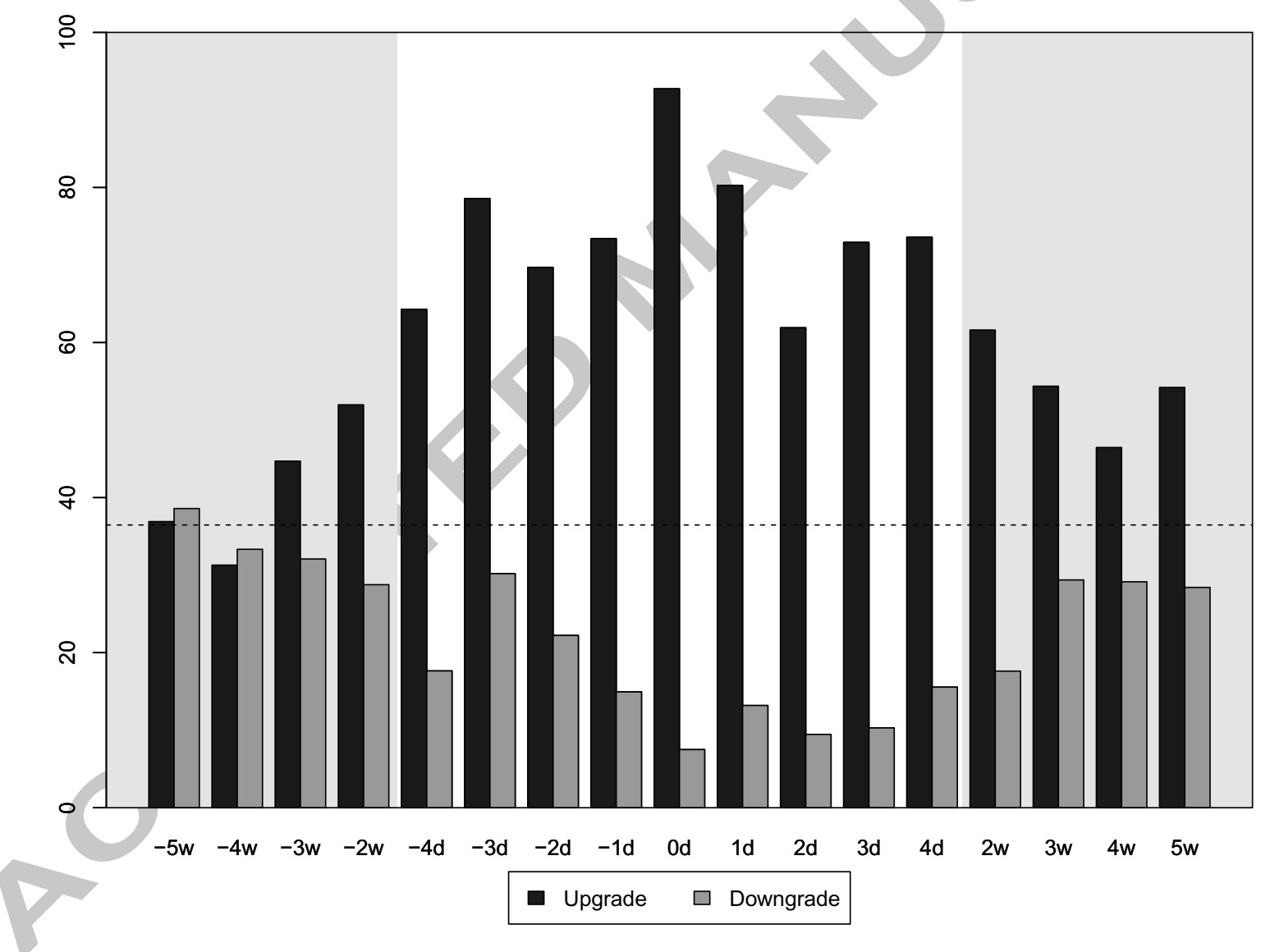


Figure 2: Trading activity around BSA recommendation revisions

This figure reports the average number of trades in a stock around the day $(\mathrm{t}=0)$ a BSA revises the stock's recommendation. The dark-shaded bars show the number of trades around upgrades, the light-shaded bars show number of trades around downgrades. Averages are taken on a daily basis for the first week around revisions (white background). For weeks -5 to -2 and 2 to 5 , the figure reports weekly averages (shaded background). The dashed line denotes the average for upgrades and downgrades over weeks -5 to -2 .

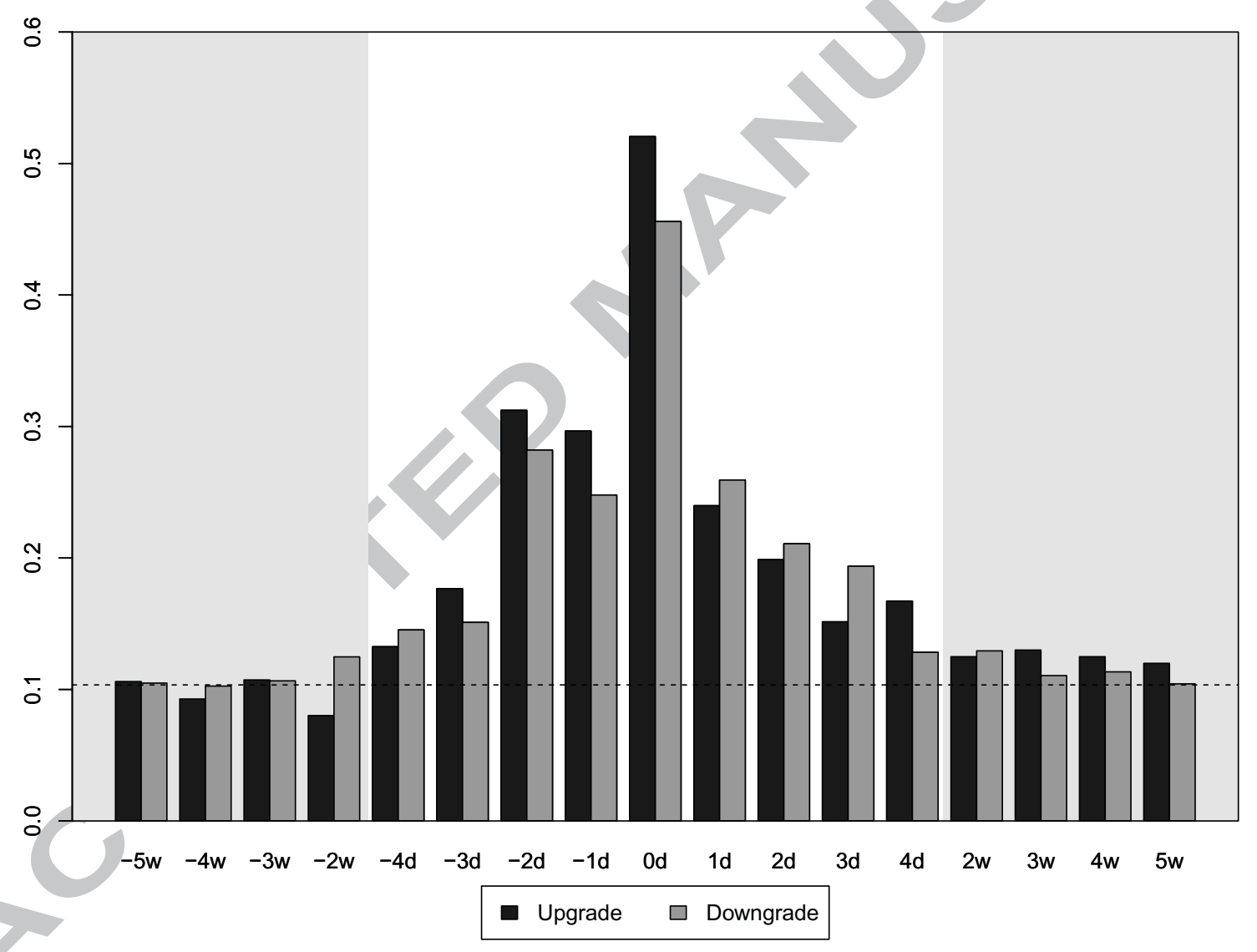


Table 1: Fund characteristics relative to the universe of same-category funds

This table reports characteristics for 13 of the 14 sample funds based on data from Morningstar websites collected in October 2008. (One sample fund is unavailable in the data due to its closure in 2007.) The table reports the number of sample funds falling into each quintile of their respective fund category as classified by Morningstar. The total number of funds used in the comparison is 697 .

\begin{tabular}{|c|c|c|c|c|c|c|}
\hline & \multicolumn{6}{|c|}{ Number of funds in category quintile } \\
\hline & (lowest) & 1 & 2 & 3 & 4 & 5 (highest) \\
\hline Assets under management & & 0 & 0 & 6 & 4 & 3 \\
\hline Total expense ratio & & 0 & 3 & 5 & 0 & 5 \\
\hline Average market capitalization of portfolio firms & & 2 & 5 & 2 & 1 & 3 \\
\hline 5 -year fund performance & & 2 & 5 & 2 & 4 & 0 \\
\hline
\end{tabular}


Table 2: Structure of recommendations by BSAs and key SSAs

This table reports information about recommendations by BSAs and key SSAs over the sample period 2004 to 2007. Key SSAs are those employed by the top 10 brokers with highest overlap of their coverage with the stocks held by the buy-side firm. The data is aggregated at broker level and presented as means over brokers with rank 1 to 5 (column SSAs Top 1-5) and brokers with rank 6 to 10 (column SSAs Top 6-10). The first five rows report the distribution of recommendations (as a percentage of all recommendations by that analyst group). Rows six to eight report the mean recommendation, the underlying number of recommendations, and the total number of analysts, respectively. The final row reports the number of distinct stocks for which recommendations are available that are also held by the buy-side firm.

\begin{tabular}{lrrr}
\hline & BSAs & SSAs Top 1-5 & SSAs Top 6-10 \\
\hline 1 (sell) & 0.4 & 3.2 & 4.2 \\
2 (underperform) & 15.4 & 15.1 & 14.0 \\
3 (hold) & 41.8 & 38.3 & 42.8 \\
4 (buy) & 36.6 & 32.5 & 25.3 \\
5 (strong buy) & 5.7 & 11.0 & 13.8 \\
Mean recommendation & 3.32 & 3.33 & 3.31 \\
No. of recommendations & 803 & 1300 & 1068 \\
No. of analysts & 40 & 199 & 136 \\
Relevant coverage & 319 & 456 & 386 \\
\hline
\end{tabular}


This table reports summary statistics for the final sample of stock transactions between January 2004 and

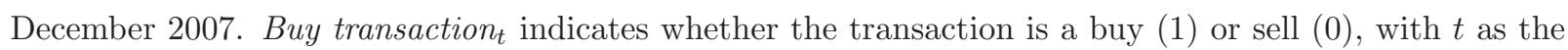

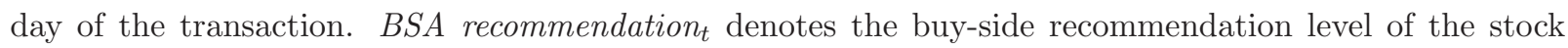
on day $t$. BSA recommendation revision $n_{\tau, \tau-i}$ is an indicator whether the BSA stock recommendation has been reduced (-1), increased $(+1)$, or is unchanged (0) within the period $\tau-i$ to $\tau$. Cash Flow $w_{\tau, \tau-i}$ is the sum of daily net cash flows (in percent of fund assets) of the fund trading the stock over the period $\tau-i$ to $\tau$. Key SSA recommendation revision ${ }_{\tau, \tau-i}$ is an indicator whether the difference between the number of upgrades and downgrades by key SSAs within the period $\tau-i$ to $\tau$ is negative (-1), positive $(+1)$, or zero (0, also indicating no revisions). Key SSAs are those employed by the top 10 brokers with highest overlap of their coverage with the stocks covered and traded by the buy-side firm. Cons. recommendation denotes the consensus recommendation level of the stock on day $t$. Cons. recommendation revision ${ }_{\tau, \tau-i}$ is the difference between the consensus recommendation value in $\tau$ and its value in $\tau-i-1$. Cons. earnings revision $_{\tau, \tau-i}$ is the percentage change in the absolute weighted consensus earnings forecast between $\tau$ and $\tau-i-1$, winsorized at $\pm 100 \%$. $\operatorname{Return}_{\tau, \tau-i}$ is the percentage change between the closing stock price in $\tau$ and $\tau-i-1$. Recommendations are coded from 1 for "sell" to 5 for "strong buy".

\begin{tabular}{|c|c|c|c|c|c|}
\hline Variable & Mean & Median & StdDev & Min & Max \\
\hline Buy transaction $_{t}$ & 0.361 & 0.000 & 0.480 & 0.0 & 1.0 \\
\hline BSA recommendation $_{t}$ & 3.634 & 4.000 & 0.707 & 1.0 & 5.0 \\
\hline BSA recommendation revision ${ }_{t+1, t-1}$ & -0.001 & 0.000 & 0.155 & -1.0 & 1.0 \\
\hline BSA recommendation revision ${ }_{t-2, t-5}$ & -0.001 & 0.000 & 0.128 & -1.0 & 1.0 \\
\hline BSA recommendation revision ${ }_{t-6, t-20}$ & -0.003 & 0.000 & 0.209 & -1.0 & 1.0 \\
\hline Cash Flow $t, t-1$ & -0.180 & -0.087 & 2.420 & -40.8 & 24.9 \\
\hline Cash Flow $t-2, t-5$ & -0.445 & -0.183 & 2.180 & -40.7 & 25.2 \\
\hline Key SSA recommendation revision ${ }_{t, t-1}$ & -0.002 & 0.000 & 0.232 & -1.0 & 1.0 \\
\hline Key SSA recommendation revision ${ }_{t-2, t-5}$ & 0.004 & 0.000 & 0.291 & -1.0 & 1.0 \\
\hline Key SSA recommendation revision ${ }_{t-6, t-20}$ & 0.012 & 0.000 & 0.502 & -1.0 & 1.0 \\
\hline Cons. recommendation $t$ & 3.672 & 3.710 & 0.381 & 2.2 & 4.8 \\
\hline Cons. recommendation revision ${ }_{t, t-5}$ & 0.001 & 0.000 & 0.058 & -1.0 & 0.6 \\
\hline Cons. recommendation revision ${ }_{t-6, t-20}$ & 0.003 & 0.000 & 0.096 & -1.0 & 1.0 \\
\hline Cons. recommendation revision ${ }_{t-21, t-120}$ & 0.037 & 0.040 & 0.227 & -1.1 & 1.1 \\
\hline Cons. earnings revision ${ }_{t, t-5}$ & 0.393 & 0.000 & 4.430 & -100.0 & 100.0 \\
\hline Cons. earnings revision $t-6, t-20$ & 1.040 & 0.000 & 6.564 & -100.0 & 100.0 \\
\hline Cons. earnings revision ${ }_{t-21, t-120}$ & 6.594 & 5.889 & 17.785 & -100.0 & 100.0 \\
\hline Return $_{t-1, t-5}$ & 0.218 & 0.212 & 4.289 & -56.2 & 41.0 \\
\hline Return $_{t-6, t-20}$ & 1.196 & 1.192 & 6.008 & -58.2 & 44.5 \\
\hline Return $_{t-21, t-120}$ & 7.584 & 7.065 & 15.005 & -67.6 & 160.4 \\
\hline No. of observations & 19,614 & & & & \\
\hline
\end{tabular}




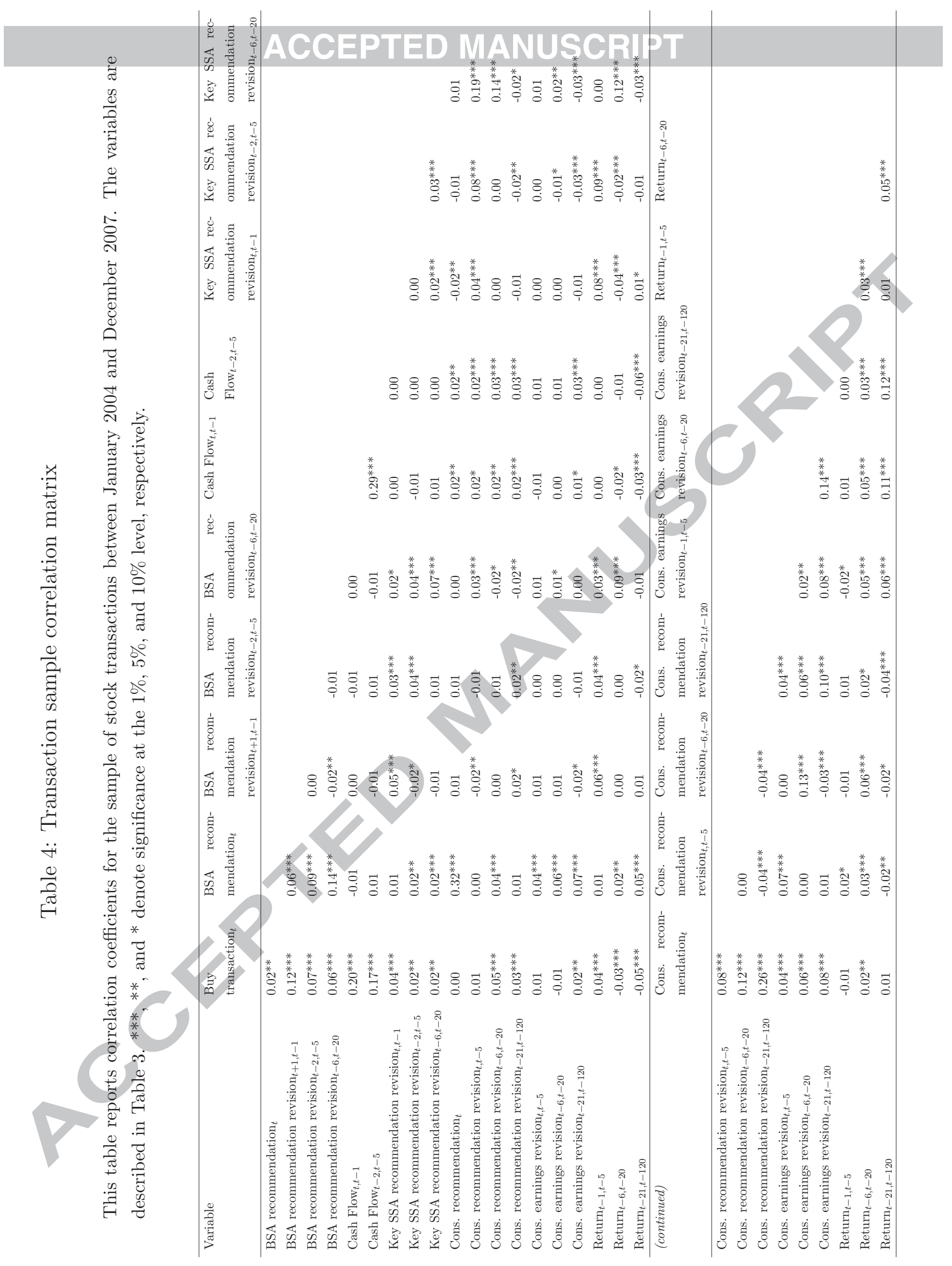


Table 5: The distribution of BSA recommendation revisions and associated transactions

This table reports in Panel A the distribution of BSA recommendation revisions for each prior recommendation level. The last column of Panel A shows the distribution of all prior recommendations. Panel B reports the percentage of buy transactions in stocks with a BSA recommendation revision by prior and new recommendation. Percentages are calculated for all transactions in the stock in the period one trading day prior to one trading day after the recommendation revision. $n t$ denotes revisions which have no transactions associated with them. Recommendations are coded from 1 for "sell" to 5 for "strong buy".

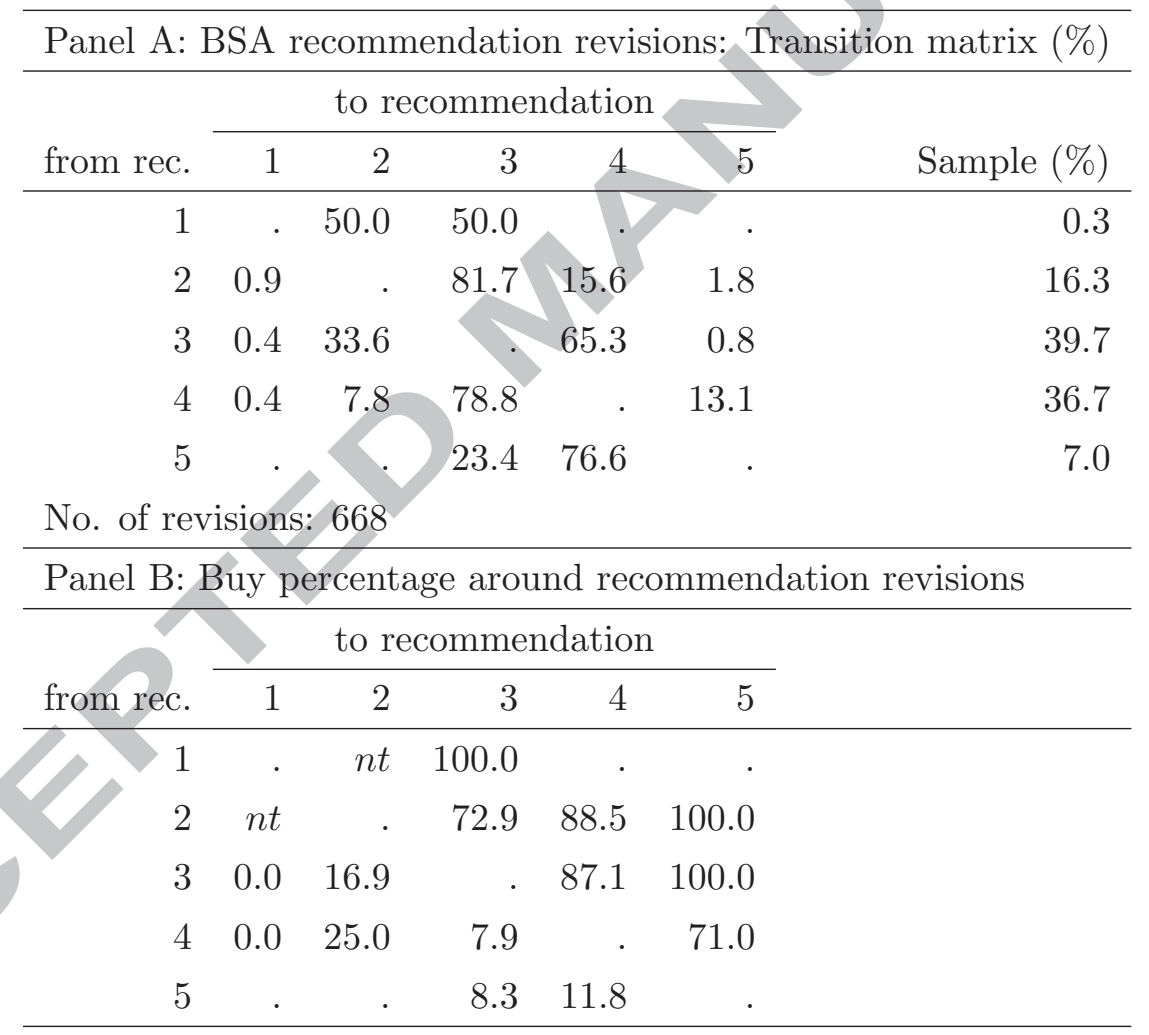


Table 6: Logit analysis of transaction sign

This table reports parameter estimates and average marginal effects for the logit analysis of fund managers'

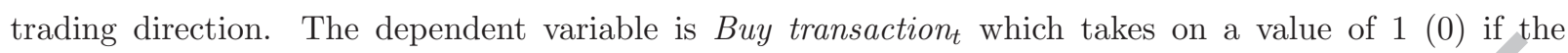
transaction on day $t$ is a buy (sell). The explanatory variables are described in Table 3. Recommendations are coded from 1 for "sell" to 5 for "strong buy". The Unit column presents the unit of the change underlying the marginal effect calculation, with pp denoting percentage points. t-statistics are given in brackets. The $R^{2}$ reported is McFadden's pseudo $R^{2}$.***,**, and * denote significance at the $1 \%, 5 \%$, and $10 \%$ level, respectively.

\begin{tabular}{|c|c|c|c|c|c|}
\hline \multirow[b]{2}{*}{ Variable } & \multirow[b]{2}{*}{ Estimate } & \multirow[b]{2}{*}{ t-stat } & \multicolumn{3}{|c|}{ Marginal Effects } \\
\hline & & & Unit & Effect & t-stat \\
\hline (Intercept) & $-0.310^{*}$ & {$[-1.88]$} & na & na & na \\
\hline $\mathrm{BSA}$ recommendation $t$ & $0.043^{*}$ & {$[1.77]$} & 1 & 0.009 & {$[1.61]$} \\
\hline BSA recommendation revision $_{t+1, t-1}$ & $2.129 * * *$ & {$[14.74]$} & 1 & 0.428 & {$[13.37]$} \\
\hline BSA recommendation revision $_{t-2, t-5}$ & $1.252^{* * *}$ & {$[8.76]$} & 1 & 0.252 & {$[7.94]$} \\
\hline BSA recommendation revision ${ }_{t-6, t-20}$ & $0.780 * * *$ & {$[9.60]$} & 1 & 0.157 & {$[8.70]$} \\
\hline Cash Flow $_{t, t-1}$ & $0.795^{* * *}$ & {$[22.64]$} & $1 \%$ & 0.160 & {$[20.65]$} \\
\hline Cash Flow $_{t-2, t-5}$ & $0.240^{* * *}$ & {$[13.10]$} & $1 \%$ & 0.048 & [11.98] \\
\hline Key SSA recommendation revision ${ }_{t, t-1}$ & $0.356^{* * *}$ & {$[5.07]$} & 1 & 0.071 & {$[4.59]$} \\
\hline Key SSA recommendation revision ${ }_{t-2, t-5}$ & $0.131^{* *}$ & {$[2.36]$} & 1 & 0.026 & {$[2.13]$} \\
\hline Key SSA recommendation revision $n_{t-6, t-20}$ & $0.076^{* *}$ & {$[2.29]$} & 1 & 0.015 & {$[2.07]$} \\
\hline Cons. recommendation ${ }_{t}$ & -0.072 & {$[-1.54]$} & 1 & -0.014 & {$[-1.40]$} \\
\hline Cons. recommendation revision ${ }_{t, t-5}$ & 0.259 & {$[0.91]$} & 1 & 0.052 & {$[0.82]$} \\
\hline Cons. recommendation revision ${ }_{t-6, t-20}$ & $0.965^{* * *}$ & {$[5.54]$} & 1 & 0.194 & {$[5.02]$} \\
\hline Cons. recommendation revision ${ }_{t-21, t-120}$ & $0.221^{* * *}$ & {$[3.00]$} & 1 & 0.044 & {$[2.72]$} \\
\hline Cons. earnings revision ${ }_{t, t-5}$ & 0.005 & {$[1.38]$} & $1 \%$ & 0.001 & {$[1.25]$} \\
\hline Cons. earnings revision $t-6, t-20$ & $-0.005^{* *}$ & {$[-2.22]$} & $1 \%$ & -0.001 & {$[-2.01]$} \\
\hline Cons. earnings revision ${ }_{t-21, t-120}$ & $0.002^{* *}$ & {$[2.12]$} & $1 \%$ & 0.000 & {$[1.92]$} \\
\hline $\operatorname{Return}_{t-1, t-5}$ & $0.008^{* *}$ & {$[2.17]$} & $1 \%$ & 0.002 & {$[1.97]$} \\
\hline $\operatorname{Return}_{t-6, t-20}$ & $-0.012^{* * *}$ & {$[-4.38]$} & $1 \%$ & -0.002 & {$[-3.97]$} \\
\hline Return $_{t-21, t-120}$ & $-0.004^{* * *}$ & {$[-4.08]$} & $1 \%$ & -0.001 & {$[-3.69]$} \\
\hline$R^{2}$ & 0.1113 & & & & \\
\hline No. of observations & 19,614 & & & & \\
\hline
\end{tabular}


Table 7: Transaction impact of alternative BSA revision variables

This table reports parameter estimates and average marginal effects for alternative specifications of the BSA revision variables resulting from logit analyses of fund managers' trading decisions as in Table 6 . The dependent variable is Buy transaction $_{t}$ which takes on a value of $1(0)$ if the transaction on day $t$ is a buy (sell). In Panel A, BSA recommendation upgrade $_{\tau, \tau-i}$ is an indicator whether the BSA stock recommendation has been increased (1) or not increased (0) within the period $\tau-i$ to $\tau$, while $B S A$ recommendation downgrade $e_{\tau, \tau-i}$ is an indicator whether the BSA recommendation has been decreased (1) or not decreased (0) within that period. In Panel B, BSA recommendation surprise s,,$-i_{\text {is }}$ equal to 1 for an upgrade and 0 for a downgrade revision minus the predicted probability of an upgrade in the stock's recommendation (derived from the logit analysis underlying Table 8) if the revision occurred within the period $\tau-i$ to $\tau$, and zero else. Both logit analyses also include the same set of other explanatory variables as in the analysis of Table 6 . Recommendations are coded from 1 for "sell" to 5 for "strong buy". t-statistics are given in brackets. The $R^{2}$ reported is McFadden's pseudo $R^{2}$. ***, **, and * denote significance at the $1 \%, 5 \%$, and $10 \%$ level, respectively.

\begin{tabular}{|c|c|c|c|c|}
\hline \multicolumn{5}{|c|}{ Panel A: Logit analysis with BSA upgrades and downgrades separated } \\
\hline \multirow[b]{2}{*}{ Variable } & \multirow[b]{2}{*}{ Estimate } & \multirow[b]{2}{*}{ t-stat } & \multicolumn{2}{|c|}{ Marginal Effects } \\
\hline & & & Effect & t-stat \\
\hline BSA recommendation upgrade ${ }_{t+1, t-1}$ & $2.452^{* * *}$ & {$[12.79]$} & 0.522 & {$[21.16]$} \\
\hline BSA recommendation upgrade $t_{-2, t-5}$ & $1.086^{* * *}$ & {$[6.09]$} & 0.263 & [6.14] \\
\hline BSA recommendation upgrade $t-6, t-20$ & $0.856^{* * *}$ & {$[7.90]$} & 0.207 & {$[7.70]$} \\
\hline BSA recommendation downgrade $t_{t+1, t-1}$ & $-1.598^{* * *}$ & {$[-7.53]$} & -0.244 & {$[-13.36]$} \\
\hline BSA recommendation downgrade $t_{t-2, t-5}$ & $-1.558^{* * *}$ & {$[-6.05]$} & -0.240 & {$[-10.58]$} \\
\hline BSA recommendation downgrade $e_{t-6, t-20}$ & $-0.684^{* * *}$ & {$[-5.65]$} & -0.133 & {$[-6.71]$} \\
\hline$R^{2}$ & 0.1117 & & & \\
\hline No. of observations & 19,614 & & & \\
\hline \multicolumn{5}{|c|}{ Panel B: Logit analysis using the surprise in BSA revisions } \\
\hline & & & \multicolumn{2}{|c|}{ Marginal Effects } \\
\hline Variable & Estimate & t-stat & Effect & t-stat \\
\hline BSA recommendation surprise st $_{t, t-1}$ & $4.379^{* * *}$ & {$[13.39]$} & 0.882 & {$[12.15]$} \\
\hline BSA recommendation surprise st-2,t-5 & $2.552^{* * *}$ & {$[8.77]$} & 0.514 & {$[7.96]$} \\
\hline BSA recommendation surprise ${ }_{t-6, t-20}$ & $1.415^{* * *}$ & {$[8.72]$} & 0.285 & {$[7.92]$} \\
\hline$R^{2}$ & 0.1094 & & & \\
\hline No. of observations & 19,550 & & & \\
\hline
\end{tabular}


Table 8: Logit analysis of BSA recommendation revisions

This table reports parameter estimates and average marginal effects for the logit analysis of buy-side analysts' recommendation revisions. The dependent variable is the direction of the recommendation change and equals 1 (0) for an upgrade (downgrade). $t$ denotes the day of the recommendation change. The explanatory variables are described in Table 3. Recommendations are coded from 1 for "sell" to 5 for "strong buy". The Unit column presents the unit of the change underlying the marginal effect calculation, with pp denoting percentage points. t-statistics are given in brackets. The $R^{2}$ reported is McFadden's pseudo $R^{2}$.***,**, and * denote significance at the $1 \%, 5 \%$, and $10 \%$ level, respectively.

\begin{tabular}{|c|c|c|c|c|c|}
\hline \multirow[b]{2}{*}{ Variable } & \multirow[b]{2}{*}{ Estimate } & \multirow[b]{2}{*}{ t-stat } & \multicolumn{3}{|c|}{ Marginal Effects } \\
\hline & & & Unit & Effect & t-stat \\
\hline (Intercept) & 0.053 & {$[0.06]$} & na & na & na \\
\hline Key SSA recommendation revision ${ }_{t, t-1}$ & $1.213^{* * *}$ & {$[3.43]$} & 1 & 0.283 & {$[3.22]$} \\
\hline Key SSA recommendation revision ${ }_{t-2, t-5}$ & $0.498^{*}$ & {$[1.69]$} & 1 & 0.116 & {$[1.58]$} \\
\hline Key SSA recommendation revision $t-6, t-20$ & 0.251 & {$[1.38]$} & 1 & 0.059 & {$[1.30]$} \\
\hline Cons. recommendation $t$ & -0.052 & {$[-0.22]$} & 1 & -0.012 & {$[-0.20]$} \\
\hline Cons. recommendation revision ${ }_{t, t-5}$ & 1.227 & {$[1.02]$} & 1 & 0.286 & {$[0.96]$} \\
\hline Cons. recommendation revision ${ }_{t-6, t-20}$ & -0.129 & {$[-0.13]$} & 1 & -0.030 & {$[-0.12]$} \\
\hline Cons. recommendation revision ${ }_{t-21, t-120}$ & 0.216 & {$[0.54]$} & 1 & 0.050 & {$[0.51]$} \\
\hline Cons. earnings revision ${ }_{t, t-5}$ & 0.033 & {$[1.34]$} & $1 \%$ & 0.008 & {$[1.26]$} \\
\hline Cons. earnings revision ${ }_{t-6, t-20}$ & $0.036^{*}$ & {$[1.93]$} & $1 \%$ & 0.008 & {$[1.81]$} \\
\hline Cons. earnings revision ${ }_{t-21, t-120}$ & 0.001 & {$[0.10]$} & $1 \%$ & 0.000 & {$[0.10]$} \\
\hline $\operatorname{Return}_{t-1, t-5}$ & $0.032^{*}$ & {$[1.91]$} & $1 \%$ & 0.008 & {$[1.79]$} \\
\hline $\operatorname{Return}_{t-6, t-20}$ & -0.026 & {$[-1.65]$} & $1 \%$ & -0.006 & {$[-1.55]$} \\
\hline Return $_{t-21, t-120}$ & -0.007 & {$[-1.18]$} & $1 \%$ & -0.002 & {$[-1.10]$} \\
\hline$R^{2}$ & 0.0485 & & & & \\
\hline No. of observations & 539 & & & & \\
\hline
\end{tabular}


Table 9: Performance of BSA revisions

This table reports \% returns of stocks upgraded and downgraded by the buy-side analysts as well as the difference in returns (in percentage points). t-statistics are given in brackets. Stock returns are calculated using closing prices, starting with the closing price on the event day, and are averaged over each return period. Panel A reports raw returns, Panel B reports abnormal returns using expected returns from a market model with the MSCI Europe index as the market index.

\begin{tabular}{|c|c|c|c|c|c|c|}
\hline & \multicolumn{2}{|c|}{ Upgrades } & \multicolumn{4}{|c|}{ Downgrades D Difference } \\
\hline & Returns & t-stat & Returns & t-stat & Returns & t-stat \\
\hline \multicolumn{7}{|c|}{ Panel A: Raw returns } \\
\hline 1 Day & 0.171 & {$[1.49]$} & -0.282 & {$[-2.25]$} & 0.453 & {$[2.67]$} \\
\hline 1 week & 0.598 & {$[2.61]$} & -0.403 & {$[-1.75]$} & 1.001 & {$[3.08]$} \\
\hline 2 weeks & 1.560 & {$[5.11]$} & -0.414 & {$[-1.25]$} & 1.974 & {$[4.38]$} \\
\hline 3 weeks & 2.062 & {$[5.25]$} & -0.164 & {$[-0.51]$} & 2.226 & {$[4.40]$} \\
\hline 1 month & 2.018 & {$[4.78]$} & -0.510 & {$[-1.42]$} & 2.527 & {$[4.56]$} \\
\hline 2 months & 2.792 & {$[4.60]$} & 0.955 & {$[1.85]$} & 1.837 & {$[2.31]$} \\
\hline 3 months & 3.405 & {$[4.51]$} & 1.658 & {$[2.52]$} & 1.747 & {$[1.74]$} \\
\hline 6 months & 5.758 & {$[5.59]$} & 4.177 & {$[4.81]$} & 1.581 & {$[1.17]$} \\
\hline \multicolumn{7}{|c|}{ Panel B: Abnormal returns } \\
\hline 1 Day & 0.192 & {$[1.91]$} & -0.371 & {$[-3.14]$} & 0.563 & {$[3.63]$} \\
\hline 1 week & 0.448 & {$[2.25]$} & -0.417 & {$[-2.12]$} & 0.865 & {$[3.09]$} \\
\hline 2 weeks & 0.874 & {$[3.22]$} & -0.681 & {$[-2.36]$} & 1.555 & {$[3.93]$} \\
\hline 3 weeks & 0.995 & {$[2.88]$} & -0.803 & {$[-2.99]$} & 1.798 & {$[4.12]$} \\
\hline 1 month & 0.816 & {$[2.19]$} & -1.193 & {$[-3.97]$} & 2.009 & [ 4.19] \\
\hline 2 months & 0.408 & {$[0.70]$} & -0.955 & {$[-2.14]$} & 1.363 & {$[1.86]$} \\
\hline 3 months & -0.167 & {$[-0.23]$} & -1.291 & {$[-2.28]$} & 1.124 & {$[1.23]$} \\
\hline 6 months & -0.293 & {$[-0.30]$} & -1.199 & {$[-1.58]$} & 0.906 & {$[0.74]$} \\
\hline No. of revisions & & 310 & & 344 & & \\
\hline
\end{tabular}




\section{ACCEPTED MANUSCRIPT}

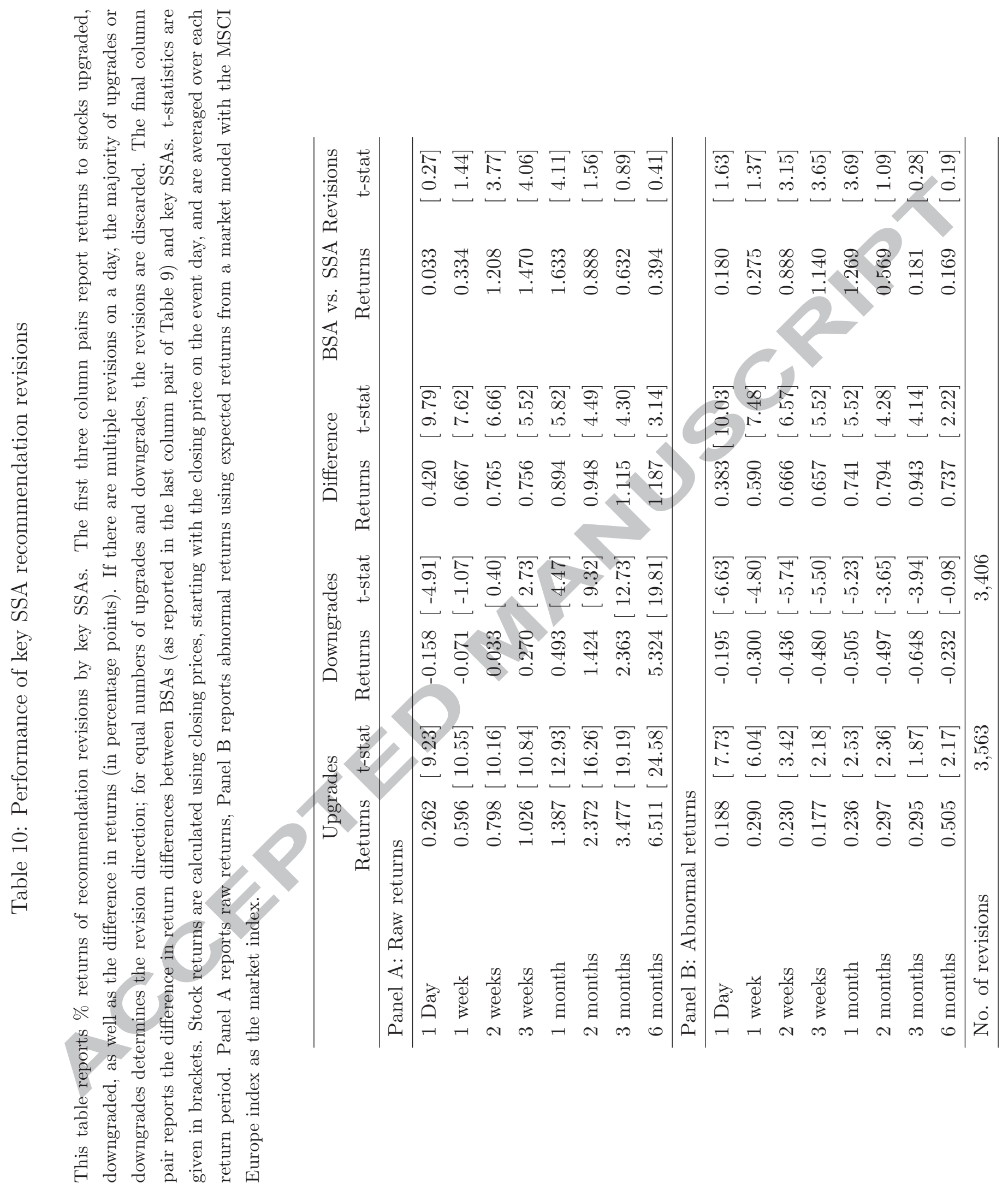




\section{ACCEPTED MANUSCRIPT}

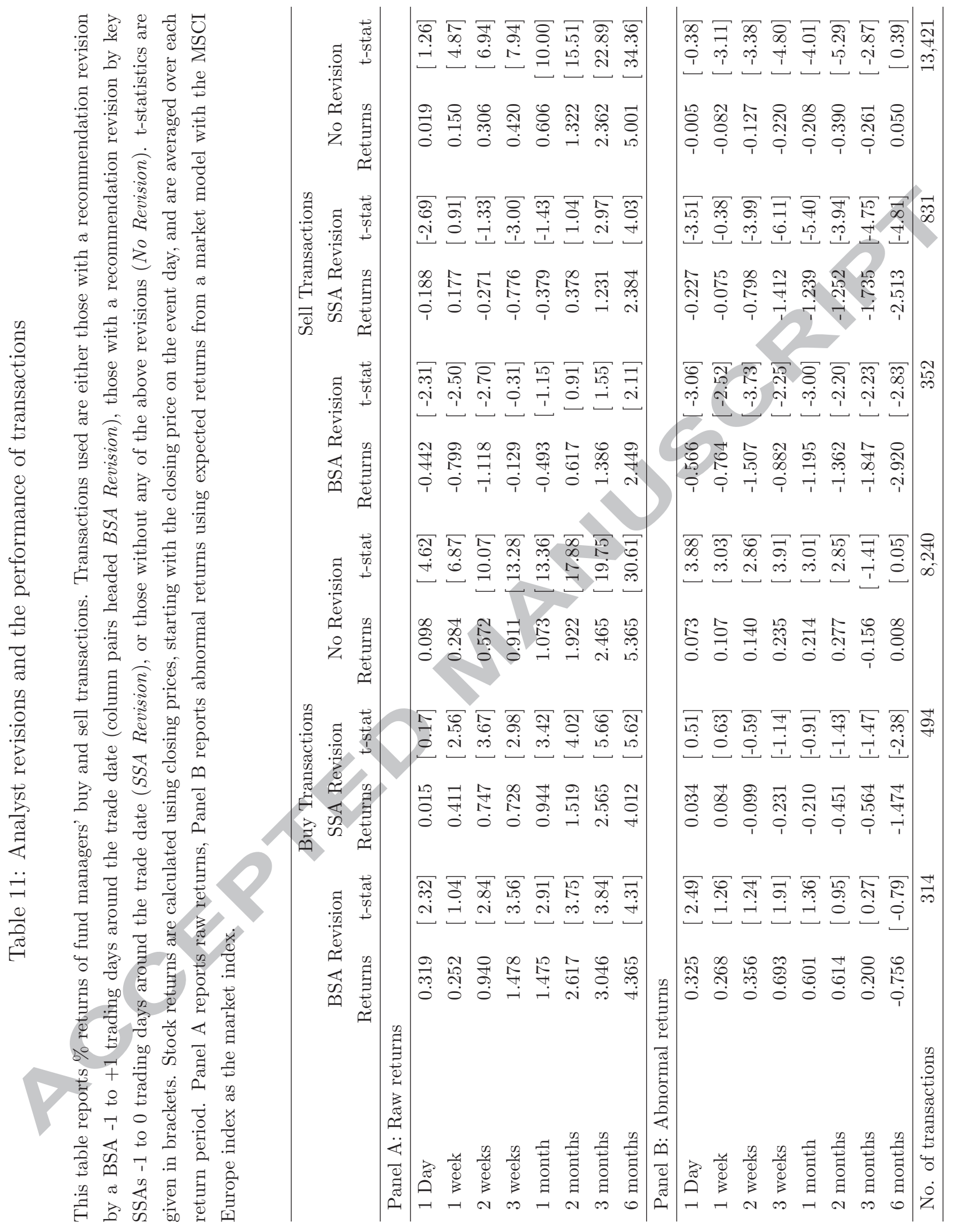



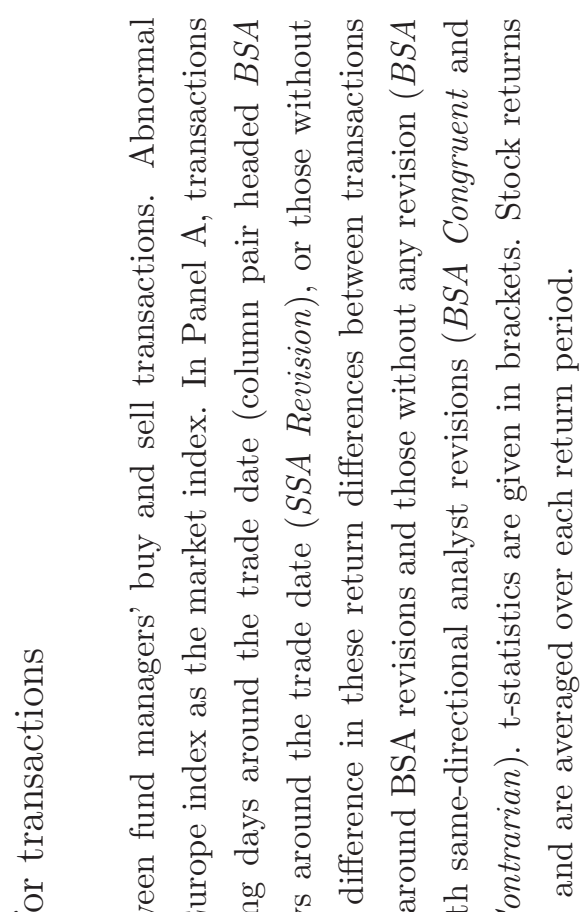

రิ)

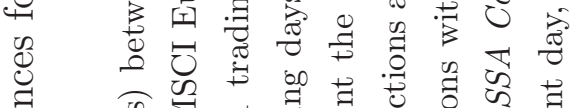

త్ర

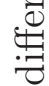

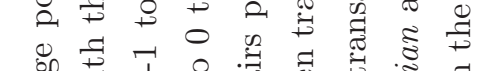

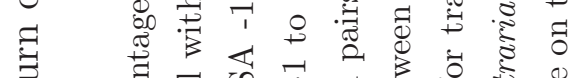

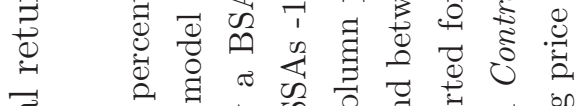

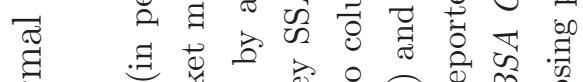

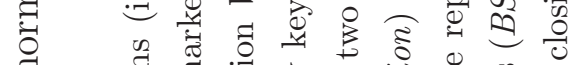

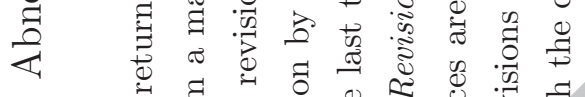

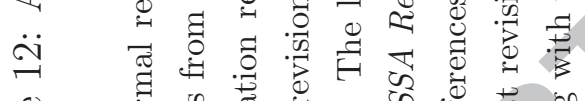

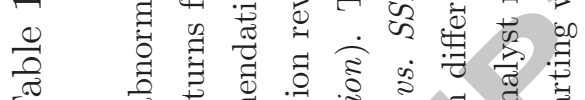

है
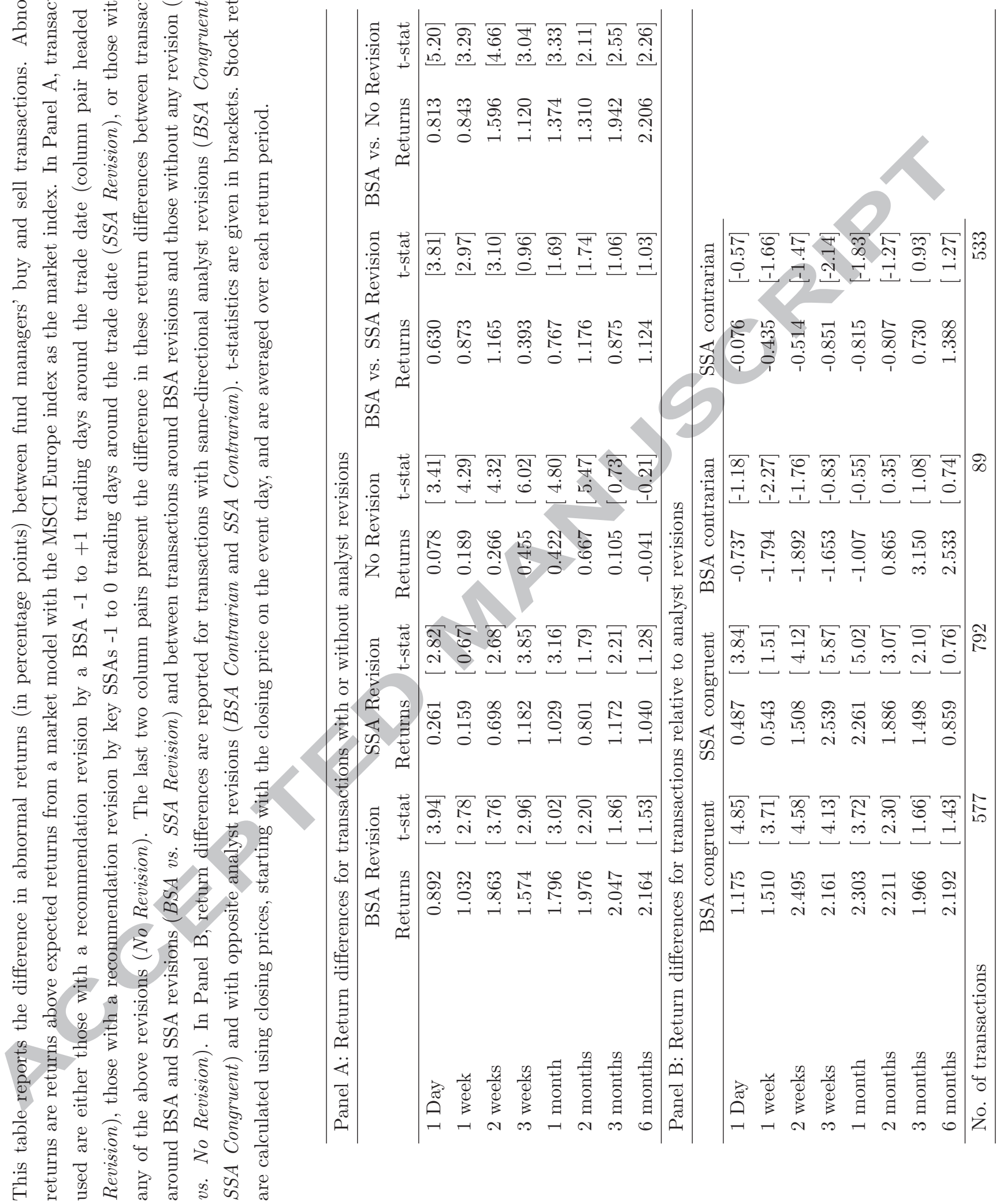


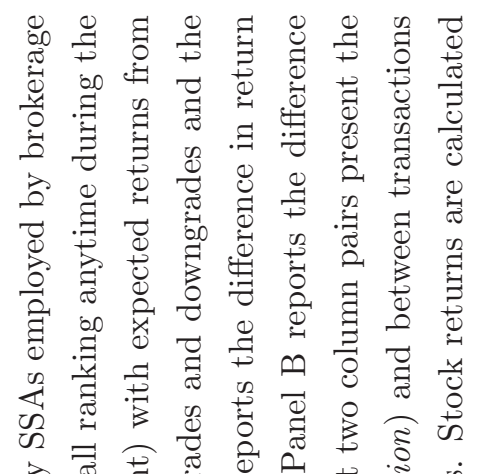

* 1

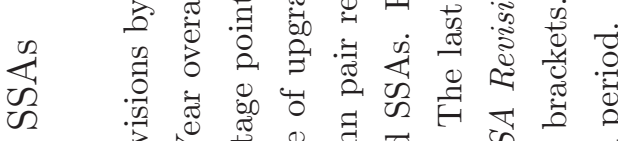

थ

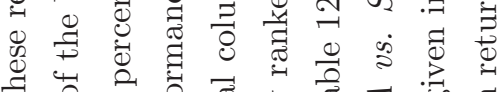

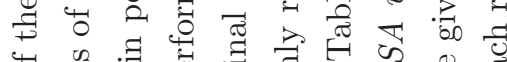

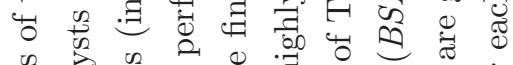

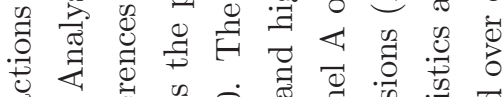

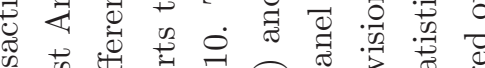

जี

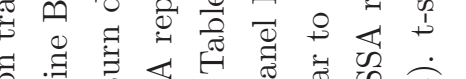

0 तี

芯

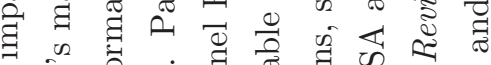

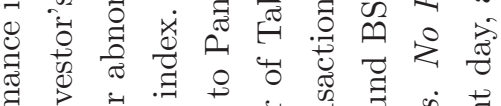

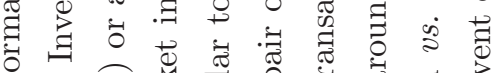

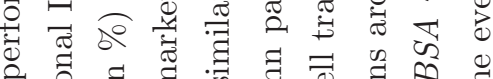

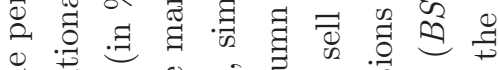

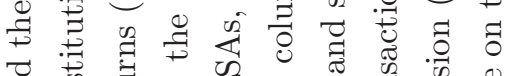

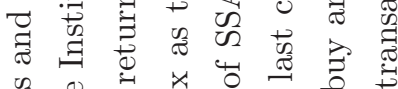

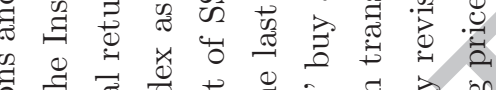

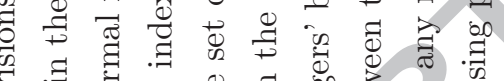

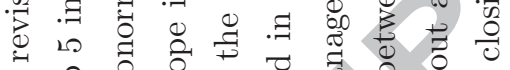

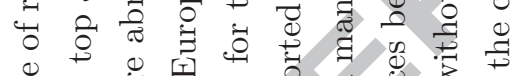

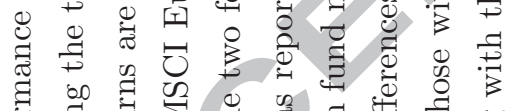

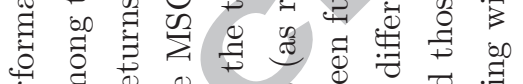

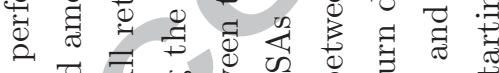

记

†

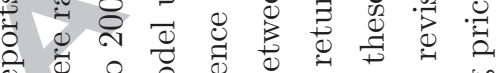

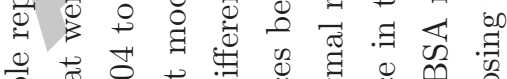

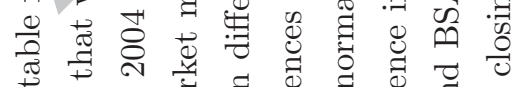

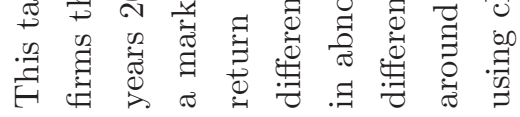

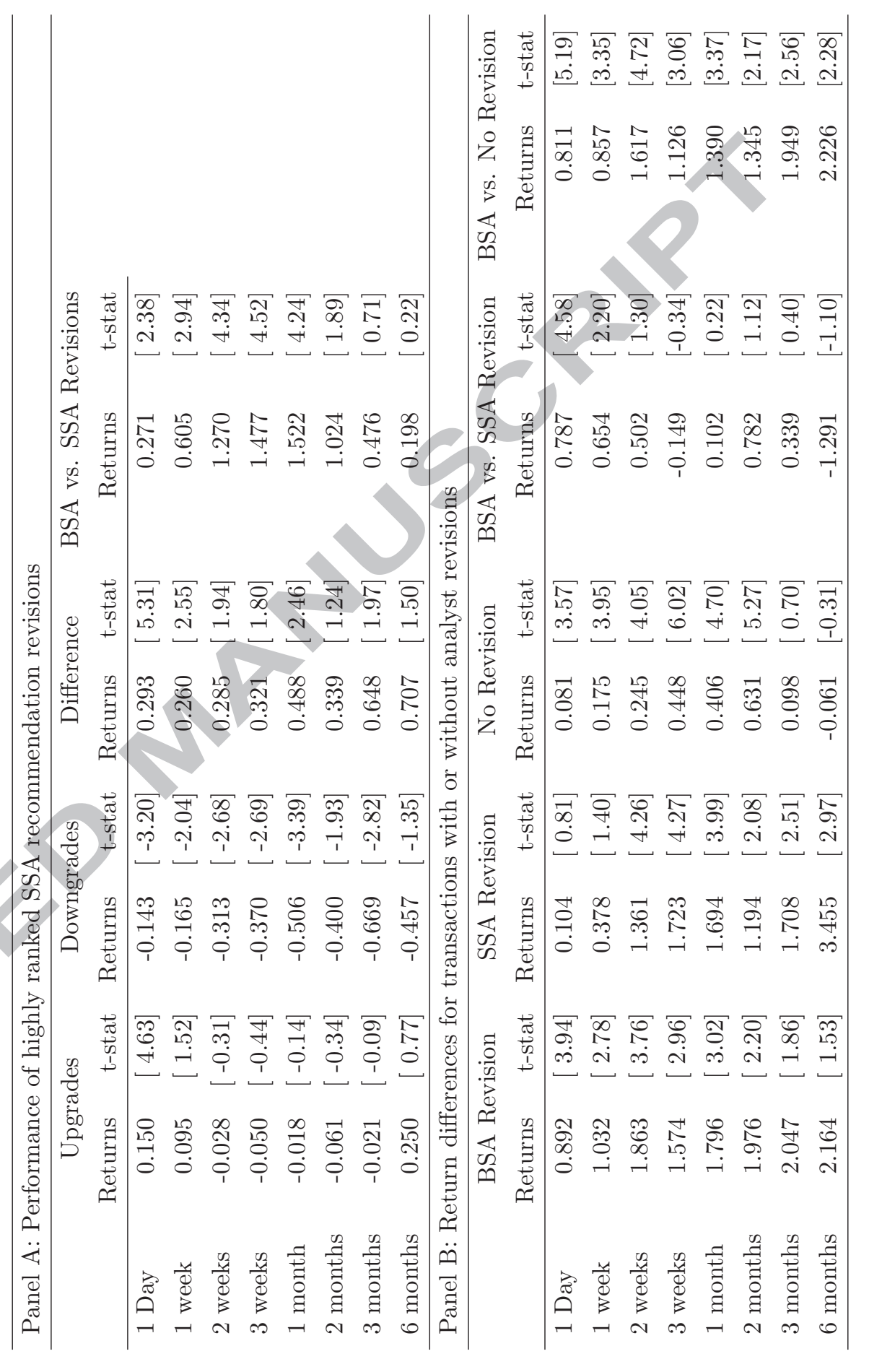


Table 14: Profits generated by BSA-induced round-trip transactions

This table reports the average realized trading profit for round-trip transactions. The transactions used are those with same-directional BSA recommendation revision -1 to +1 trading days around the initial trade date that also have subsequent transactions reverting the initial trade. Profits are calculated without market adjustment (Raw profits), adjusted for an equal investment in the MSCI Europe index (Marketadjusted profits) and for a beta-adjusted investment into the MSCI Europe index ( $\beta$-adjusted profits). Stock prices used are reported transaction prices. Profits are calculated both gross and net of transaction costs. Transaction costs applied to the benchmark or risk-adjusted benchmark investment are 5 basis points. t-statistics are given in brackets.

\begin{tabular}{lrrrr}
\hline & \multicolumn{2}{c}{ Gross of transaction costs } & \multicolumn{2}{c}{ Net of transaction costs } \\
& Mean $(€)$ & t-stat & Mean $(€)$ & t-stat \\
\hline Raw profits & 110,043 & {$[2.55]$} & 98,996 & {$[2.30]$} \\
Market-adjusted profits & 77,596 & {$[1.87]$} & 69,454 & {$[1.67]$} \\
$\beta$-adjusted profits & 53,342 & {$[1.41]$} & 45,245 & {$[1.19]$} \\
\hline No. of round-trips & 349 & & & \\
\hline
\end{tabular}




\section{The Influence of Buy-side Analysts on Mutual Fund Trading}

\section{Highlights:}

- We present evidence on the trading and performance impact of buy-side analysts.

- Fund managers strongly follow recent recommendation revisions.

- Trades triggered by buy-side recommendations have higher returns than other trades.

- The impact of buy-side analysts is more pronounced than that of sell-side analysts. 